Journal of Thermal Engineering, Vol. 7, No. 4, pp. 845-866, May, 2021

Yildiz Technical University Press, Istanbul, Turkey

\title{
A NUMERICAL STUDY OF ENTROPY GENERATION ON OLDROYD-B NANOFLUID FLOW PAST A RIGA PLATE
}

\author{
Zachariah Mbugua Mburu ${ }^{1}$, Sabyasachi Mondal ${ }^{*}$, Precious Sibanda ${ }^{3}$, Ramprakash Sharma $^{4}$
}

\begin{abstract}
This study investigates entropy generation due to the unsteady boundary layer flow of an Oldroyd-B nanofluid past a Riga plate. The velocity, temperature and concentration fields are obtained and the flow equations solved numerically using the spectral collocation method with overlapping grids. The local entropy generation distribution is obtained by solving the entropy generation equation numerically. Sensitivity and convergence analysis is performed to demonstrate the accuracy and convergence of the numerical method. The effect of principal flow parameters on entropy generation is investigated and it is established that entropy generation is directly proportional to the width of the Riga plate, Brinkman number, Prantl number and the Brownian motion parameter. It is further shown that the entropy generation is inversely proportional to the Eckert number and Deborah number in relaxation time. The range of parameter values were obtained from the reported literature. The current study may have applications of physics, including in the design of both cooling and heating devices.
\end{abstract}

Keywords: Entropy Generation, Overlapping Grids, Relaxation and Retardation Time, Oldroyd-B Nanofluid, Hyperbolic Time-Varying Boundary Conditions, Riga Plate

\section{INTRODUCTION}

The quantity of energy produced in any thermodynamic process is conserved from the second law of thermodynamics, although the quality may degrade with the process. The reduction in the quality of energy produced in any thermodynamic process is measured by entropy generation. The quality and quantity of energy produced in a thermodynamic process reduces with the increase in entropy generation. A Riga plate, also commonly known as an electromagnetic actuator is a device consisting of permanent magnets and electrodes of equal width. The flow control device was first developed by Gailitis et al. [1] and Avilov [2] renamed it a Riga plate. Hayat et al. [3] investigated the impact of nonlinear mixed convection and radiation along a Riga plate with double stratification. The homotopy method was used to solve the system of differential equations. It was established that the effects of radiation and temperature ratio variables enhanced heat distribution. The buoyancy ratio and the modified Hartman number had the opposite effect on the rate of heat transfer. The study of entropy generation due to the unsteady nanofluid flow past a Riga plate is of great interest to researchers. It has applications such as in cooling of automotive vehicles, heat exchangers and heat sinks, solar energy collectors and cooling towers. Heat and mass transfer are often accompanied by entropy production, which often reduces energy in many thermodynamic processes. For this reason, focusing on the irreversibility of heat transfer processes and seeking to understand the impact of entropy generation makes engineering sense. For example, a good heat exchanger design essentially means thermodynamic efficiency. The art of modifying a dynamical system so that it destroys the least available work subject to different boundary constraints is the key focus of entropy generation minimization.

Rana et al. [4] reported on a study of entropy generation due to Ohmic heating in a nanofluid flow under the influence of a varying magnetic field. Nayak et al. [5] used the Buongiorno model of a nanofluid to study the influence of magnetic forces on the slip flow over a Riga plate with internal heating. The influence of variable thermal conductivity on nonlinear Sisko fluid flow past an electromagnetic sheet with entropy production was reported by Shaw et al. [6]. Das et al. [7] determined the effects of Soret and Dufour parameters on unsteady Casson fluid flow past a Riga plate. They reported that the skin friction coefficient is enhanced by increasing the Dufour parameter and the Biot number. Recent studies on energy produced This paper was recommended for publication in revised form by Regional Editor Hatice Mercan

1,3 School of Mathematics, Statistics and Computer Science, University of KwaZulu-Natal, Pietermaritzburg, South Africa

${ }^{2}$ Department of Mathematics, Amity University Kolkata, Newtown - 700135, West Bengal, India

${ }^{4}$ DepartmentofMechanical Engineering, National Institute of Technology, Arunachal Pradesh, India

${ }^{\star}$ E-mail address: sabya.mondal.2007@gmail.com

Orcid id: 0000-0002-2916-2922, 0000-0003-4666-0568, 000-0003-2115-4642, 0000-0002-3359-1316

Manuscript Received 05 December 2019, Accepted 09 May 2020 
in a thermodynamic process are given by [8-13].

The use of nanofluids is one of the modern techniques used to enhance heat transfer in thermodynamic devices $[14,15]$. To improve the sustainability of heat transfer devices and improve their efficiency, researchers have investigated the major causes of entropy generation in different dynamical systems $[16,17]$. Entropy generation has been shown to be linked to the geometry of a device and the thermophysical properties of the working fluid [18]. Rehman et al. [19] investigated entropy generation in a radiative rotating nanofluid with thermal slip. The shooting method was used in solving the system of differential equations. It was established that the Bejan number has the effect of reducing the nanoparticle volume fraction. Also, gold nanoparticles produced the maximum entropy when compared to silver and copper oxide nanoparticles. Nanofluids are efficient energy transfer with marginal entropy generation. Related studies on heat transfer in nanofluids are given by [20-25].

Esfahani et al. [26] investigated the influence of a wavy wall and nanoparticles on entropy generation in flow past a heat exchanger plate. The finite volume technique was used to solve the system of differential equations. The simulations were done using the Ansys-fluent software. The entropy generation reduced along the centerline where friction does not play a significant role. Bhatti et al. [27] studied entropy generation in a magneto hydrodynamic boundary layer generated by a rotating surface using the successive linearization method to solve the flow equations. They found that with an increase in the suction parameter, both the velocity profiles and entropy generation increased. Shashikumar et al. [28] investigated entropy generation analysis in magneto-nanofluids containing aluminum and titanium alloy nanoparticles in a micro-channel with partial slip and convective conditions. The dimensionless flow equations were solved by applying the RungeKutta numerical method. They found that entropy production can be reduced by increasing radiative parameter, Joule heating parameter and viscous dissipation.

Moreover, entropy generation was higher in the case of titanium-water nanofluids than aluminum-water nanofluids. Related literature on nanofluids and entropy generation can be found in ref. [29-33].

The impact of entropy generation and nonlinear thermal radiation on Darcy-Forchheimer flow of a Manganese Iron Oxide $\left(\mathrm{MnFe}_{2} \mathrm{O}_{4}\right)$ Casson-water nanofluid due to a rotating disk and its application to brain dynamics was reported by Shaw et al. [34]. They found that entropy generation affects how the brain functions. Farooq et al. [35] investigated transpiration and viscous dissipation impact on entropy generation in nanofluid flow past a nonlinear radially stretching sheet. The numerical solution was obtained using the shooting technique and the bvp4c Matlab solver. It was found that entropy generation within the laminar flow was high compared to the surface of the stretching sheet. The laminar motion of an electrically conducting fluid can be reduced by applying an external magnetic field. The applied magnetic field was shown to reduce entropy generation in the fluid flow.

Recently, Gupta et al. [36] investigated the MHD flow of an Oldroyd-B nanofluid past a bidirectional stretching sheet. The differential equations were solved using the differential transformation technique and Padé approximations. It was found that the velocity decreased with an increasing magnetic parameter, the temperature profiles increased with an increase in the magnetic parameter, Deborah number of the first kind and the Brownian motion parameter. However, it decreased with an increase in the Deborah number of the second kind. Alshomrani et al. [37] investigated chemically reactive MHD flow and energy transport in an Oldroyd-B nanofluid subject to stratifications. The homotopy method was used for the computation of solutions of the nonlinear flow equations. They found that an increase in both the Biot number and chemical reaction parameter led to a mass transfer reduction.

Gireesha et al. [38] recently investigated chemical reaction effects on fluid flow and concentration transport past a Riga plate with solutal slip impact. The system of differential equations was solved using the Runge-Kutta method. Nayak et al. [39] investigated the effects of homogeneous- heterogeneous reactions on radiative sodium chloride-carbon nanofluid flow past a heated vertical plate. They noted that the momentum, thermal and concentration boundary layer thicknesses reduced due to a Lorentz force's effect. Related studies are reported by [40-42].

The analysis of heat transfer in boundary layer problems is fundamental in industrial processes. Heat 
transfer in fluids involving open and closed systems is mainly explained by the first law of thermodynamics [43]. The law of thermodynamics is useful for investigating the temperature distribution within a thermodynamic system and the rate of heat transfer at the solid boundary [44]. There are several causes for entropy generation in any thermodynamic process, including fluid friction, chemical reactions, mixing of fluids, dissipative forces, among others, Bejan [45].

Entropy generation due to unsteady Oldroyd-B nanofluid flow past a Riga Plate has not received much attention in the literature. The current study investigates the impact of principal parameters such as the width parameter of the Riga plate, Brinkman number, Eckert number, Hartman number, Reynolds number and Brownian motion parameter on entropy generation for Oldroyd-B nanofluid past a Riga plate. We further present an analysis of accuracy and convergence of the spectral collocation numerical method with overlapping grids. This study may have applications in the cooling of machine parts, food processing and drying of cylinder-shaped bodies, considering shrinkage at different drying temperatures.

\section{MATHEMATICAL FORMULATION}

In the study, we consider an incompressible boundary layer time-varying flow of an Oldroyd-B nanofluid past a Riga plate. The study takes into account entropy generation, thermophoretic motion and Brownian diffusion. We take $u$ and $v$ to be respectively the velocity components in the $x$ and $y$ directions where the $x$-axis is measured along the plate and the $y$-axis is at right angle to it as shown in Figure 1, see [46]. The electromagnetic field $M_{h}$ of the Riga-plate yields a wall-parallel Lorentz force of exponentially decaying nature. The boundary layer equations with Boussinesq approximation and the assumptions set out above are

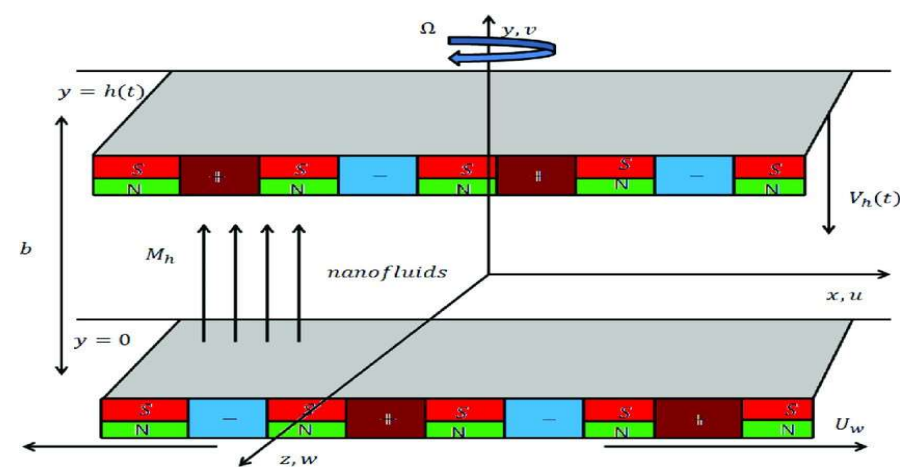

Figure 1. Flow configuration, where $N$ and $S$ are the North pole and the South pole, respectively of the magnet

Continuity equation

$$
\frac{\partial u}{\partial x}+\frac{\partial v}{\partial y}=0
$$

Momentum equation

$$
\begin{gathered}
\frac{\partial u}{\partial t}+u \frac{\partial u}{\partial x}+v \frac{\partial u}{\partial y}+\Gamma_{1}\left(u^{2} \frac{\partial^{2} u}{\partial x^{2}}+v^{2} \frac{\partial^{2} u}{\partial y^{2}}+2 u v \frac{\partial^{2} u}{\partial x \partial y}\right)=\frac{\pi j_{0} M_{h}}{8 \rho_{f}} \exp ^{-\left(\frac{\pi}{d}\right) y}+ \\
v_{f}\left[\frac{\partial^{2} u}{\partial y^{2}}+\Gamma_{2}\left(u \frac{\partial^{3} u}{\partial x \partial y^{2}}+v \frac{\partial^{3} u}{\partial y^{3}}-\frac{\partial u}{\partial x} \frac{\partial^{2} u}{\partial y^{2}}-\frac{\partial u}{\partial y} \frac{\partial^{2} v}{\partial y^{2}}\right)\right]
\end{gathered}
$$

Energy equation

$$
\frac{\partial T}{\partial t}+u \frac{\partial T}{\partial x}+v \frac{\partial T}{\partial y}=\frac{k_{f}}{\left(\rho C_{p}\right)_{f}}\left(\frac{\partial^{2} T}{\partial y^{2}}\right)+\tau\left[D_{B} \frac{\partial C}{\partial y} \frac{\partial T}{\partial y}+\frac{D_{T}}{T_{\infty}}\left(\frac{\partial T}{\partial y}\right)^{2}\right]+\frac{\Gamma_{1}}{\Gamma_{2}} \frac{\mu}{\left(\rho C_{p}\right)_{f}}\left(\frac{\partial u}{\partial y}\right)^{2}-\frac{1}{\left(\rho C_{p}\right)_{f}}\left(\frac{\partial q^{r}}{\partial y}\right)
$$


Journal of Thermal Engineering, Research Article, Vol. 7, No. 4, pp. 845-866, May, 2021

Species concentration equation

$$
\frac{\partial C}{\partial t}+u \frac{\partial C}{\partial x}+v \frac{\partial C}{\partial y}=D_{B} \frac{\partial^{2} C}{\partial y^{2}}+\frac{D_{T}}{T_{\infty}} \frac{\partial^{2} T}{\partial y^{2}}-K_{1}\left(C-C_{\infty}\right)
$$

The model time-varying boundary conditions are given by

$$
\begin{aligned}
& t=0: u=v=0, T=T_{\infty}, C=C_{\infty},(x, y \geqslant 0), \\
& u=u_{w}(t, x), v=0, T=T_{w}, C=C_{w},(y=0), \\
& t>0: u=u_{e}(t, x), T \rightarrow T_{\infty}, C \rightarrow C_{\infty}, \text { as } y \rightarrow \infty,
\end{aligned}
$$

where, $u_{w}(x, t)=\frac{a x}{1+\zeta t}, u_{e}(x, t)=\frac{b x}{1+\zeta t}, T_{w}=T_{\infty}+\frac{T_{0} x^{m}}{1+\zeta t}$ and $C_{w}=C_{\infty}+\frac{C_{0} x^{n}}{1+\zeta t}$. Eqs. (2-4) are transformed to ordinary differential equations using the variables $u=\frac{a x}{1+\zeta t} F_{\eta}(\eta), v=-\sqrt{\frac{a v_{f}}{1+\zeta t}} F(\eta), \theta(\eta)=\frac{T-T_{\infty}}{T_{w}-T_{\infty}}, \phi(\eta)=\frac{c-C_{\infty}}{C_{w}-C_{\infty}}$ and $\eta=y \sqrt{\frac{a}{v_{f}(1+\zeta t)}}$. From Eq.(3), the radiative heat flux $q^{r}$ is described by the Rosseland approximation, [47]

$$
q^{r}=-\frac{4 \sigma_{1}}{3 \chi} \frac{\partial T^{4}}{\partial y}
$$

The fluid-phase temperature difference within the flow is assumed to be sufficiently small [47] such that $T^{4}$ may be expanded in a Taylor series about the free-stream temperature $T_{\infty}$ and neglecting higher-order terms to yield

$$
T^{4}=4 T_{\infty}^{3} T-3 T_{\infty}^{4}
$$

Substituting Eq. (5) in the last term of Eq. (3) yields

$$
\frac{\partial q^{r}}{\partial y}=-\frac{16{ }_{1} T_{\infty}^{3}}{3 \chi} \frac{\partial^{2} T}{\partial y^{2}}
$$

We then substitute the transformation variables into Eqs. (2-5) to have

$$
\begin{gathered}
F_{\eta \eta \eta}+\Omega_{2}\left[\left(F_{\eta \eta}\right)^{2}-F F_{\eta \eta \eta}\right]+\Omega_{1}\left(2 F F_{\eta} F_{\eta \eta}-F^{2} F_{\eta \eta \eta}\right)+F F_{\eta \eta}-\left(F_{\eta}\right)^{2}+\frac{1}{2} \varepsilon \eta F_{\eta \eta}+\varepsilon F_{\eta}+H_{a} e^{-\delta \eta}=0 \\
\left(1+\frac{4 R_{d}}{3}\right) \theta_{\eta \eta}+P_{r}\left[N_{b} \theta_{\eta} \phi_{\eta}+N_{t}\left(\theta_{\eta}\right)^{2}+F \theta_{\eta}+\frac{1}{2} \varepsilon \eta \theta_{\eta}+2 E_{c} \frac{\Omega_{2}}{\Omega_{1}}\left(F_{\eta \eta}\right)^{2}\right]=0 \\
\phi_{\eta \eta}+\frac{N_{t}}{N_{b}} \theta_{\eta \eta}-S_{c}\left(F \phi_{\eta}+\frac{1}{2} \varepsilon \phi_{\eta}+\gamma \phi\right)=0 .
\end{gathered}
$$

The boundary conditions for Eqs. (8-10) are obtained as $F_{\eta}=1, F=0, \theta=1, \phi=1$ at $\eta=0$ and $F_{\eta}=\beta, \theta \rightarrow 0, \phi \rightarrow 0$ as $\eta \rightarrow \infty$.

The parameters in Eqs. (8- 10) are given by $\Omega_{1}=\frac{a \Gamma_{1}}{1+\zeta \mathrm{t}}, \Omega_{2}=\frac{\mathrm{a} \Gamma_{2}}{1+\zeta \mathrm{t}}, \varepsilon=\frac{\tau}{\mathrm{a}}, \mathrm{H}_{\mathrm{a}}=\frac{\pi \mathrm{j}_{0} \mathrm{M}_{\mathrm{h}} \mathrm{x}(1+\zeta \mathrm{t})^{2}}{8 \rho_{\mathrm{f}} \mathrm{u}_{\mathrm{w}}^{2}}$,

$\delta=\frac{\pi}{\mathrm{d} \sqrt{\frac{\mathrm{a}}{\mathrm{v}_{\mathrm{f}}(1+\zeta \mathrm{t})}}}, \operatorname{Pr}=\frac{v}{\alpha}, E c=\frac{u_{w}^{2}}{\left(c_{p}\right)_{f}\left(T_{w}-T_{\infty}\right)}, N_{b}=\frac{\tau D_{B}\left(C_{w}-C_{\infty}\right)}{v_{f}}, N_{t}=\frac{\tau D_{T}\left(T_{w}-T_{\infty}\right)}{T_{\infty} v_{f}}, S_{c}=\frac{v}{D_{B}}, \gamma=\frac{K_{0}}{a}, \beta=\frac{b}{a} \quad$ and $R_{d}=\frac{\sigma_{1} T_{\infty}^{3}}{3 k \chi}$. 


\section{ENTROPY GENERATION ANALYSIS}

There are several causes of entropy production: fluid friction, dissipative forces, mixing of chemical particles, heat transfer, viscous forces, unrestrained expansion and contraction. In this study, the volumetric rate of local entropy generation for an Oldroyd-B nanofluid past an electromagnetic actuator with thermal radiation and the magnetic fields can be expressed as, see [48]

$$
S_{\text {gen }}=\underbrace{\frac{k_{f}}{T_{\infty}^{2}}\left[\left(\frac{\partial T}{\partial y}\right)^{2}+\frac{16 \sigma_{1} T_{\infty}^{3}}{\partial y^{2}} \frac{\partial^{2} T}{\partial y^{2}}\right]}_{1^{\text {st }} \text { part }}+\underbrace{\frac{v_{f}}{T_{\infty}}\left(\frac{\partial u}{\partial y}\right)^{2}}_{2^{\text {nd }} \text { part }}+\underbrace{\frac{H a_{0}^{2}}{T_{\infty}} u^{2}}_{3^{\text {rd }} \text { part }}+\underbrace{\frac{R_{d} D_{B}}{C_{\infty}}\left(\frac{\partial C}{\partial y}\right)^{2}+\frac{R_{d} D_{B}}{T_{\infty}}\left(\frac{\partial T}{\partial y} \frac{\partial C}{\partial y}\right)}_{4^{\text {th }} \text { part }}
$$

In Eq.(11), the entropy is in four parts. The first term is the entropy due to thermal radiation irreversibility, the second is entropy due to viscous dissipation irreversibility, the third is entropy due to the applied magnetic field irreversibility and the fourth part is entropy due to diffusive irreversibility. Entropy generation is defined as the ratio of local volumetric entropy generation to the characteristic rate of entropy generation expressed as

$$
N_{G}=\frac{S_{g e n}}{S_{0}}
$$

where,

$$
S_{0}=\frac{k_{f}\left(T_{w}-T_{\infty}\right)^{2}}{T_{\infty}^{2}}
$$

Using Eqs. (11-13), the dimensionless entropy generation is expressed as

$$
N_{G}=R_{e}\left(1+N_{b}\right)\left(\theta_{\eta}\right)^{2}+\frac{B_{r}}{\psi}\left(F_{\eta}\right)^{2}+\frac{B r\left(H_{a}\right)^{2}}{\psi}\left(F_{\eta}\right)^{2}+\Lambda\left(\frac{\varrho}{\psi}\right)^{2}\left(\phi_{\eta}\right)^{2}+\Lambda\left(\frac{\varrho}{\psi}\right)\left(\phi_{\eta} \theta_{\eta}\right)
$$

The dimensionless terms in Eq. (14) are defined as $R e=\frac{V_{0} u}{v}, B r=\frac{\mu_{f} u_{w}^{2}}{k \Delta T_{\infty}}, \Psi=\frac{T_{w}-T_{\infty}}{T_{\infty}}, \varrho=\frac{C_{w}-C_{\infty}}{C_{\infty}}$ and $\Lambda=\frac{R_{d} D_{B}}{C_{\infty}}$

\section{METHOD OF SOLUTION}

This section describes the spectral collocation method with overlapping grids for a system of highly nonlinear ordinary differential equations defined over a large computational domain. The nonlinear system of ODEs is first linearized using the quasilinearization method (QLM) of Bellman and Kalaba [49]. The linearized system is then solved using the spectral collocation method applied on overlapping grids. The truncated computational domain is subdivided into equal overlapping subintervals and an approximate solution computed over the entire domain. The overlapping is such that two grid points at the end of each subinterval coincide with neighboring subintervals. The grid points lead to less dense matrices that require less computational time to invert, leading to an efficient method. The well-posed nature of the resulting linear ODEs is demonstrated by calculating the condition number of the coefficient matrices. A well-conditioned system guarantees stability, which consequently leads to accurate results.

The system of Eqs. (8-10) are first simplified using QLM to give

$$
\begin{gathered}
a_{0, r} f_{r+1}^{\prime \prime \prime}+a_{1, r} f_{r+1}^{\prime \prime}+a_{2, r} f_{r+1}^{\prime}+a_{3, r} f_{r+1}=R_{1, r}, \\
b_{0, r} \theta_{r+1}^{\prime \prime}+b_{1, r} \theta_{r+1}^{\prime}+b_{2, r} f_{r+1}^{\prime \prime}+b_{3, r} f_{r+1}+b_{4, r} \phi_{r+1}^{\prime}=R_{2, r}, \\
c_{0, r} \phi_{r+1}^{\prime \prime}+c_{1, r} \phi_{r+1}^{\prime}+c_{2, r} \phi_{r+1}+c_{3, r} f_{r+1}+c_{4, r} \theta_{r+1}^{\prime \prime}=R_{3, r} .
\end{gathered}
$$


The boundary conditions are expressed as $f^{\prime}=1, f=0, \theta=1, \phi=1$, at $\eta=0$ and $f^{\prime}=$ $\beta, \theta \rightarrow 0, \phi \rightarrow 0$ as $\eta \rightarrow \infty$. The variable coefficients on the left-hand side of Eqs. (15-17) are expressed as

$$
\begin{aligned}
& a_{0, r}=1-\Omega_{2} f_{r}-\Omega_{1} f_{r}^{2}, a_{1, r}=2\left(\Omega_{2} f_{r}^{\prime \prime}+\Omega_{1} f_{r} f_{r}^{\prime}\right)+f_{r}+\frac{1}{2} \varepsilon \eta, a_{2, r}=2 \Omega_{2} f_{r} f_{r}^{\prime \prime}-2 f_{r}^{\prime}+\varepsilon, \\
& a_{3, r}=-\Omega_{2} f_{r}^{\prime \prime}+2 \Omega_{1} f_{r}^{\prime} f_{r}^{\prime \prime}-\Omega_{1} f_{r}^{\prime \prime \prime}+f_{r}^{\prime \prime}, b_{0, r}=1+\frac{4 R_{d}}{3}, b_{2, r}=4 P_{r} E_{c} \frac{\Omega_{2}}{\Omega_{1}} f_{r}^{\prime \prime}, b_{3, r}=P_{r} \theta_{r}^{\prime}, \\
& b_{1, r}=\operatorname{Pr}\left[N_{b} \phi_{r}^{\prime}+2 N_{t} \theta_{r}^{\prime}+f_{r}+\frac{1}{2} \varepsilon \eta\right], \quad b_{4,4}=P_{r} N_{b} \theta_{r}^{\prime} \quad c_{0, r}=1, \quad c_{1, r}=-S_{c}\left(f_{r}+\frac{1}{2} \varepsilon\right), \\
& c_{2, r}=\gamma, \quad c_{3, r}=-S_{c} \phi_{r}^{\prime} \text { and } c_{4, r}=\frac{N_{t}}{N_{b}} .
\end{aligned}
$$

The right-hand side of Eqs. (15-17) consist of nonlinear terms expressed as

$$
\begin{gathered}
R_{1, r}=\Omega_{2}\left[\left(f_{r}^{\prime \prime}\right)^{2}-f_{r} f_{r}^{\prime \prime \prime}\right]+\Omega_{1}\left(2 f_{r} f_{r}^{\prime} f_{r}^{\prime \prime}-f_{r}^{2} f_{r}^{\prime \prime \prime}+f_{r} f_{r}^{\prime \prime}-\left(f_{r}^{\prime}\right)^{2}+H_{a} e^{-\delta \eta}\right) \\
R_{2, r}=P_{r}\left[N_{b} \theta_{r}^{\prime} \phi_{r}^{\prime}+N_{t}\left(\theta_{r}^{\prime}\right)^{2}+f_{r} \theta_{r}^{\prime}+2 E_{c} \frac{\Omega_{2}}{\Omega_{1}}\left(f_{r}^{\prime \prime}\right)^{2}\right] \\
R_{3, r}=-S_{c} f_{r} \phi_{r}^{\prime}
\end{gathered}
$$

Here, $r=1,2 \ldots$ denotes the iteration level. Starting with an initial approximation, Eqs. (15- 17) are solved iteratively until a solution with the desired accuracy is realized. The spatial domain $\eta \in[0, \infty)$ is first truncated to $\left[0, L_{\eta}\right]$ where $L_{\eta}$ is large enough to approximate conditions at infinity. The truncated domain $\left[0, L_{\eta}\right]$ is decomposed into $q$ overlapping subintervals of equal lengths expressed as $\kappa_{l}=\left[\eta_{l-1}, \bar{\eta}_{l}\right], \eta_{l-1} \eta_{l} \bar{\eta}_{l}, \eta_{0}=0, \quad \bar{\eta}_{q}=L_{\eta}, \quad l=$ $1,2,3, \ldots, q$ where $\eta_{l} \bar{\eta}_{l}$ depicts the overlapping nature of the grid points. The overlapping domain decomposition in $\eta$ is as shown in Figure 2.

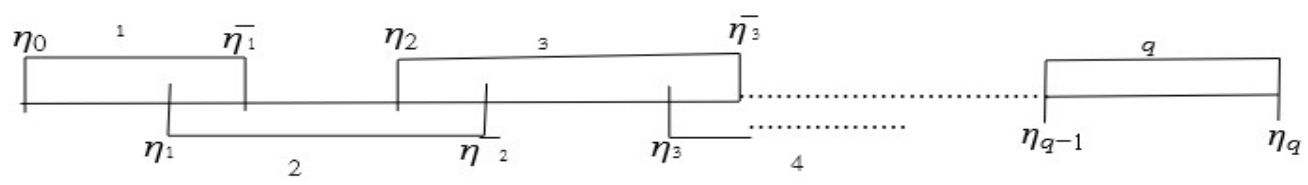

Figure 2. Overlapping grid in $\eta$

The computational domain $\left[\eta_{l-1}, \bar{\eta}_{l}\right]$ in the $l^{\text {th }}$ subinterval is transformed into $\eta^{*} \in[-1,1]$ where the standard Chebyshev differential matrix is defined by applying the linear map

$$
\eta^{*}=\frac{2}{\bar{\eta}_{l}-\eta_{l-1}}\left[\eta-\frac{1}{2}\left(\bar{\eta}_{l}+\eta_{l-1}\right)\right], \quad \eta \in\left[\eta_{l-1}-\bar{\eta}_{l}\right]
$$

Further, each subinterval is discretized into $N_{\eta}+1$ Chebyshev Gauss Lobatto points. The subintervals in the decomposed domain overlap such that the last two points in the $\iota_{l}$ subinterval overlap with the first two points of the $\wedge_{l+1}$ subinterval and they remain common. The collocation nodes in the $l^{\text {th }}$ subinterval in $\eta$ are defined in $[50]$ by

$$
\eta_{i}=\cos \left(\frac{\pi i}{N_{\eta}}\right), \text { for } i=0,1,2, \ldots N_{\eta}, \eta \in[-1,1]
$$

To obtain an explicit expression for the length of each subinterval given by $L=\bar{\eta}_{l}-\eta_{l-1}$ in terms of the number of subintervals $q$, we find 


$$
q L-L(q-1)\left(\frac{1}{2}-\frac{1}{2} \cos \left\{\frac{\pi}{N_{\eta}}\right\}\right)=b-a
$$

to obtain

$$
L=\frac{b-a}{q+(1-q)\left(\frac{1}{2}-\frac{1}{2} \cos \left\{\frac{\pi}{N_{\eta}}\right\}\right)}
$$

From Eq. (24), we obtain the following relation

$$
\bar{\eta}_{l}=\eta_{l}+L\left(\frac{1}{2}-\frac{1}{2} \cos \left\{\frac{\pi}{N_{\eta}}\right\}\right)
$$

Eq.(29) is used in defining the boundaries of the overlapping sub-intervals when performing discretization. The numerical solutions to the system of Eqs. (8-10) are approximated using Lagrange bivariate interpolating polynomials expressed as $f(\eta) \approx \sum_{q=0}^{N_{\eta}} f\left(\eta_{q}\right) L_{q}(\eta), \theta(\eta) \approx \sum_{q=0}^{N_{\eta}} \theta\left(\eta_{q}\right) L_{q}(\eta)$ and $\phi(\eta) \approx$ $\sum_{q=0}^{N_{\eta}} \phi\left(\eta_{q}\right) L_{q}(\eta)$

Here $L_{q}(\eta)$ is the standard Lagrange polynomial. The interpolating polynomial is applied in finding the approximation of discrete derivatives of the unknown functions. The derivatives of $F=(f, \theta, \phi)$ with respect to $\eta$ are approximated at the collocation points $\left(\eta_{i}\right)$ for $i=0,1,2, \ldots, N_{\eta}$ as

$$
\frac{\partial^{p} F_{r+1}\left(\eta_{i}\right)}{\partial \eta^{p}}=\stackrel{l}{\boldsymbol{D}^{p}} \boldsymbol{F}_{i, r+1}=\left(\frac{2}{L_{\eta}}\right)^{p} \sum_{k=0}^{N_{\eta}} \stackrel{l}{D_{i, k}} F_{r+1}\left(\eta_{k}\right)
$$

where,

$$
\stackrel{l}{\boldsymbol{D}}=\left(\frac{2}{L_{\eta}}\right) \stackrel{l}{D}_{i, k} \quad \text { for } \quad i, k=0,1,2, \ldots, N_{\eta}
$$

here $\stackrel{l}{D_{i, k}}, j, k=0,1,2, \ldots, N_{\eta}$ denotes an $\left(N_{\eta}+1\right) \times\left(N_{\eta}+1\right)$ standard Chebyshev differentiation matrix and the factor $\left(2 / L_{\eta}\right)$ is as a result of the application of the chain rule of differentiation, vector $F_{j, r+1}$ can be expressed as

$$
F_{i, r+1}=\left[F_{r+1}\left(\eta_{0}\right), F_{r+1}\left(\eta_{1}\right), F_{r+1}\left(\eta_{2}\right), F_{r+1}\left(\eta_{3}\right), \ldots, F_{r+1}\left(\eta_{N_{\eta}}\right)\right]^{\check{T}}
$$

where $\breve{T}$ denotes a matrix transpose. The solution is computed simultaneously across all subintervals and a matrix of coefficients is assembled. To achieve this, since the last two points in the $l^{\text {th }}$ subinterval and the first two points in the $(l+1)^{\text {th }}$ sub-interval overlap and remain common, we discard the rows corresponding to the repeated grid points and assemble the Chebyshev differentiation matrix as shown below. 


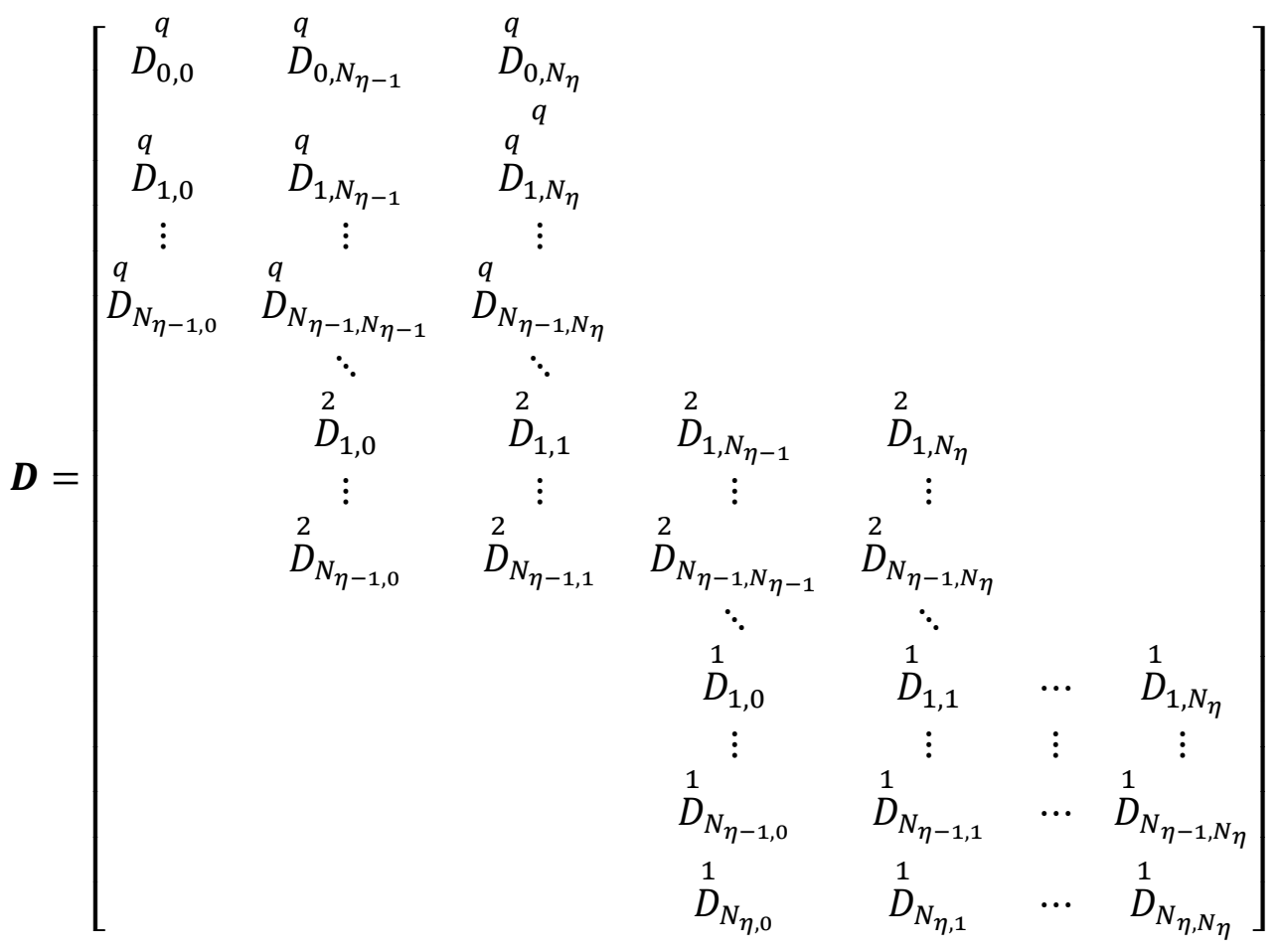

Here, the empty entries of the matrix $\boldsymbol{D}$ are zeros and $\stackrel{q}{D}$ represents the Chebyshev differentiation matrix in space variable $\eta$. The size of the matrix $\boldsymbol{D}$ is $(N+1) \times(N+1)$. The higher ordered differentiation matrices are obtained by matrix multiplication $\boldsymbol{D}^{2}, \boldsymbol{D}^{3}, \boldsymbol{D}^{4}, \ldots \boldsymbol{D}^{n}$. Using the assembled differentiation matrices, Eqs. (15-17) is expressed as a system of equations given by

$$
\begin{aligned}
& A_{1,1}^{i} F_{i, r+1}+A_{1,2}^{i} \boldsymbol{\Theta}_{\boldsymbol{i}, \boldsymbol{r}+\mathbf{1}}+A_{1,3}^{i} \boldsymbol{\Phi}_{i, \boldsymbol{r}+\mathbf{1}}=\boldsymbol{R}_{\mathbf{1}, \boldsymbol{r}} \\
& A_{2,1}^{i} \boldsymbol{F}_{\boldsymbol{i}, \boldsymbol{r + 1}}+A_{2,2}^{i} \boldsymbol{\Theta}_{\boldsymbol{i}, \boldsymbol{r}+\mathbf{1}}+A_{2,3}^{i} \boldsymbol{\Phi}_{i, \boldsymbol{r}+\mathbf{1}}=\boldsymbol{R}_{\mathbf{2}, \boldsymbol{r}}, \\
& A_{3,1}^{i} \boldsymbol{F}_{\boldsymbol{i}, \boldsymbol{r}+\mathbf{1}}+A_{3,2}^{i} \boldsymbol{\Theta}_{\boldsymbol{i}, \boldsymbol{r + 1}}+A_{3,3}^{i} \boldsymbol{\Phi}_{i, \boldsymbol{r}+\mathbf{1}}=\boldsymbol{R}_{\mathbf{3}, \boldsymbol{r}}
\end{aligned}
$$

The coefficients in Eqs. (30-32) are expressed as

$$
\begin{aligned}
& A_{1,1}^{i}=a_{0, r} \boldsymbol{D}^{\mathbf{3}}+a_{1, r} \boldsymbol{D}^{\mathbf{2}}+a_{2, r} \boldsymbol{D}+a_{3, r} \boldsymbol{I}, \quad A_{1,2}^{i}=0, \quad A_{1,3}^{i}=0, \\
& A_{2,1}^{i}=b_{2, r} \boldsymbol{D}^{\mathbf{2}}+b_{3, r} \boldsymbol{D}, \quad A_{2,2}^{i}=b_{0, r} \boldsymbol{D}^{\mathbf{2}}+b_{1, r} \boldsymbol{D}, \quad A_{2,3}^{i}=b_{4, r} \boldsymbol{D}, \\
& A_{3,1}^{i}=c_{3, r} \boldsymbol{I}, \quad A_{3,2}^{i}=c_{4, r} \boldsymbol{D}^{\mathbf{2}} \text { and } A_{3,3}^{i}=c_{0, r} \boldsymbol{D}^{\mathbf{2}}+c_{1, r} \boldsymbol{D}+c_{2, r} \boldsymbol{I} .
\end{aligned}
$$

Here $I$ represent an identity matrix of size $\left(N_{\eta}+1\right) \times\left(N_{\eta}+1\right)$. The system of Eqs. (30-32) can be expressed as a matrix system of the form 


$$
\left[\begin{array}{lll}
A_{1,1}^{i} & A_{1,2}^{i} & A_{1,3}^{i} \\
A_{2,1}^{i} & A_{2,2}^{i} & A_{2,3}^{i} \\
A_{3,1}^{i} & A_{3,2}^{i} & A_{3,3}^{i}
\end{array}\right]\left[\begin{array}{l}
F_{r+1} \\
\boldsymbol{\Theta}_{r+1} \\
\boldsymbol{\Phi}_{r+1}
\end{array}\right]=\left[\begin{array}{l}
R_{1 r} \\
R_{2 r} \\
R_{3 r}
\end{array}\right]
$$

The boundary conditions are imposed on the matrix system and evaluated at the collocation points for each subinterval as $f_{r+1}\left(N_{\eta}\right)=0, f_{r+1}^{\prime}\left(N_{\eta}\right)=1, \theta_{r+1}\left(N_{\eta}\right)=1, \phi_{r+1}\left(N_{\eta}\right)=1$ and $f_{r+1}^{\prime}(0)=\beta, \theta_{r+1}(0)=0$, $\phi_{r+1}(0)=0$.

Starting with the initial approximation, the system is solved iteratively until a solution with the desired accuracy is realized

\section{CONVERGENCE OF SOLUTIONS}

A comparison of the numerical results was made against published literature in Table 1. It was found that the findings are consistent with the published results, see [46]. The spectral collocation method with overlapping grids is thus reliable in solving boundary value problems. Sensitivity analysis for the system of differential equations was also done. This is essential for testing the method's accuracy and understanding the impact of small changes to an input variable on the solutions. To test our method's stability, the reciprocal condition number was calculated for the matrices and presented in Table 2. We note that the reciprocal condition number is relatively small that the matrices used are well-conditioned. This is an essential step in confirming the accuracy of the solutions and the overlapping grid spectral collocation method's stability. It was also noted the central processing unit (CPU) time is relatively small, indicating the method is efficient in solving boundary value problems.

Table 1. A comparison of reported literature results with the present results

\begin{tabular}{cccccc|ccc}
\hline \multicolumn{7}{c}{ Hayat at el. [46] } & \multicolumn{3}{c}{ Current results } \\
\hline $\mathbf{P r}$ & $\mathbf{E c}$ & $\mathbf{B r}$ & $f[0]$ & $-\theta[0]$ & $-\varphi[0]$ & $f[0]$ & $-\theta[0]$ & $-\varphi[0]$ \\
\hline 0.71 & 10.50 & 0.10 & 1.96871 & 0.237534 & 0.632846 & 1.97821781 & 0.23735723 & 0.63282430 \\
1.0 & & & 1.54903 & 0.529374 & 0.629509 & 1.54801713 & 0.52937338 & 0.62950321 \\
2.0 & & & 1.37220 & 0.670280 & 0.622038 & 1.37211146 & 0.67027662 & 0.62102739 \\
\hline 0.70 & 12.10 & 0.10 & 1.68425 & 0.337882 & 0.633256 & 1.68423080 & 0.33788452 & 0.63325546 \\
& 14.10 & & 1.69051 & 0.29549 & 0.633719 & 1.69050310 & 0.29548573 & 0.63371797 \\
\hline 0.71 & 10.50 & 0.70 & 1.39653 & 0.352877 & 0.621139 & 1.39651831 & 0.35287083 & 0.62103738 \\
& & 1.20 & 2.01524 & 0.318826 & 0.660435 & 2.01525741 & 0.31892553 & 0.66042310 \\
\hline
\end{tabular}

Table 2. Reciprocal condition number using $N_{\eta}=30, q=5$

\begin{tabular}{llcc}
\hline Iterations & $\mathrm{t}$ & CPU time (Picoseconds) & Condition number \\
\hline 1 & 0.4 & 0.40869 & $1.2164 \mathrm{e}+03$ \\
2 & 0.9 & 0.52877 & $1.2316 \mathrm{e}+03$ \\
3 & 1.5 & 0.59214 & $1.2328 \mathrm{e}+03$ \\
4 & 1.9 & 0.69153 & $2.2437 \mathrm{e}+03$ \\
5 & 2.5 & 0.73419 & $2.24565+03$ \\
6 & 3.0 & 0.81735 & $2.24634+03$ \\
\hline
\end{tabular}

Convergence analysis is the process of determining the rate at which an approximation approaches the exact solution. To determine the convergence of the numerical method, the infinity error norm is computed between two successive iterations as

$$
\left|E_{r+1}\right|_{\infty}=\max _{0 \leq \eta \leq T}\left|F_{r+1}^{N}-F_{r}^{N}\right|
$$

where $r$ is the number of iterations. Tables 3 and 4 show that after the sixth iteration, both the residual and exact 
errors are small, implying that the numerical method has converged.

Table 3. Infinity error norm between successive iterations using $N \eta=30, q=5$

\begin{tabular}{lccr}
\hline Iterations & \multicolumn{3}{c}{ Infinity error norm } \\
\hline $\mathrm{r}$ & $\left\|f_{r+1}-f_{r}\right\|_{\infty}$ & $\left\|\theta_{r+1}-\theta_{r}\right\|_{\infty}$ & $\left\|\varphi_{r+1}-\varphi_{r}\right\|_{\infty}$ \\
\hline 1.0 & $2.4312 \mathrm{e}-2$ & $5.1312 \mathrm{e}-2$ & $1.2164 \mathrm{e}-3$ \\
2.0 & $3.2394 \mathrm{e}-6$ & $3.2402 \mathrm{e}-3$ & $1.1316 \mathrm{e}-4$ \\
3.0 & $1.8213 \mathrm{e}-9$ & $6.6318 \mathrm{e}-5$ & $1.2328 \mathrm{e}-6$ \\
4.0 & $1.1347 \mathrm{e}-12$ & $1.5332 \mathrm{e}-8$ & $2.2437 \mathrm{e}-7$ \\
5.0 & $2.4312 \mathrm{e}-14$ & $2.7372 \mathrm{e}-12$ & $1.0467 \mathrm{e}-10$ \\
6.0 & $1.6342 \mathrm{e}-16$ & $1.0462 \mathrm{e}-14$ & $1.5233 \mathrm{e}-15$ \\
\hline CPU time (Picoseconds) & 0.31273 & 0.28271 & 0.25261
\end{tabular}

Table 4: Overlapping grid spectral collocation approximations using $N_{\eta}=30, q=5$

\begin{tabular}{llll}
\hline Iterations & & Residual error & \\
\hline $\mathrm{r}$ & $\left\|f_{r+1}\right\|_{\infty}$ & $\left\|\theta_{r+1}\right\|_{\infty}$ & $2.1164 \mathrm{e}-2$ \\
1.0 & $5.1316 \mathrm{e}-1$ & $4.0312 \mathrm{e}-3$ & $1.8206 \mathrm{e}-4$ \\
2.0 & $4.2394 \mathrm{e}-4$ & $3.2402 \mathrm{e}-4$ & $2.4328 \mathrm{e}-8$ \\
3.0 & $3.1215 \mathrm{e}-7$ & $2.1318 \mathrm{e}-6$ & $2.2437 \mathrm{e}-9$ \\
4.0 & $2.0347 \mathrm{e}-9$ & $1.4332 \mathrm{e}-8$ & $1.0476-12$ \\
5.0 & $2.1312 \mathrm{e}-11$ & $1.2372 \mathrm{e}-12$ & $1.1437-15$ \\
6.0 & $1.2372 \mathrm{e}-15$ & $1.0562 \mathrm{e}-16$ & 0.20382 \\
\hline CPU time(picoseconds) & 0.24361 & 0.23347 & \\
\hline
\end{tabular}

\section{DISCUSSION}

The influence of the Hartman number, width parameter, thermophoresis parameter, Reynolds number, Brinkman number, temperature difference parameter, concentration difference parameter, diffusion coefficient, Brownian motion parameter, Deborah number in both relaxation time and retardation time, Eckert number and Prandtl number on entropy generation is presented in Figures $3-20$. The parameters used in this work is taken from published literature see [46] with air as the fluid. The parameter values are, unless stated otherwise $E c=$ $10.5, \operatorname{Pr}=0.71, S c=0.5, \varepsilon=0.5, \delta=0.41, \beta=0.3, \Lambda=0.28, N_{t}=0.7$ and $R_{d}=0.43$.

Figure 3 demonstrates that an increase in the Brinkman number leads to an increase in entropy generation. The Brinkman number measures the importance of the heat generated by viscous heating to heat transferred by molecular conduction. The higher the value, the slower the conduction of heat produced by viscous dissipation and thus the higher the temperature leading to increased irreversibility. It is also observed that the effects of entropy generation are more prominent near the Riga plate's surface and decrease as the distance from the plate increases. Figure 4 demonstrates the influence of the Eckert number on entropy generation. Increasing the Eckert number leads to a decrease in the entropy generation with minimum values at the centerline of the channel and the opposite occurs near the upper plate. The reduced rate of advective transport is experienced at the plates due to the dominant effects of the magnetic forces leading to higher viscous dissipation causing entropy generation to increase near the Riga plate walls. This effect is expected from the nature of Eq.(12). Figure 5 shows the influence of the concentration difference number on entropy production. Higher values of the concentration difference parameter lead to increased entropy generation. This is expected as more mass is transported, causing both the velocity and thermal boundary layer thickness to increase, leading to a rise in entropy generation 
Journal of Thermal Engineering, Research Article, Vol. 7, No. 4, pp. 845-866, May, 2021

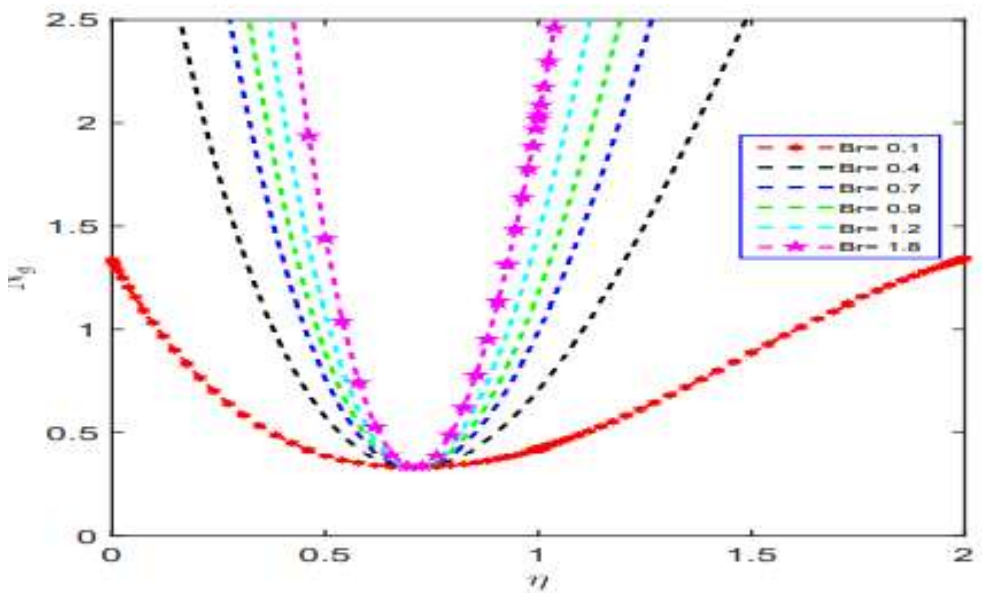

Figure 3. Influence of Brinkmann number on entropy generation

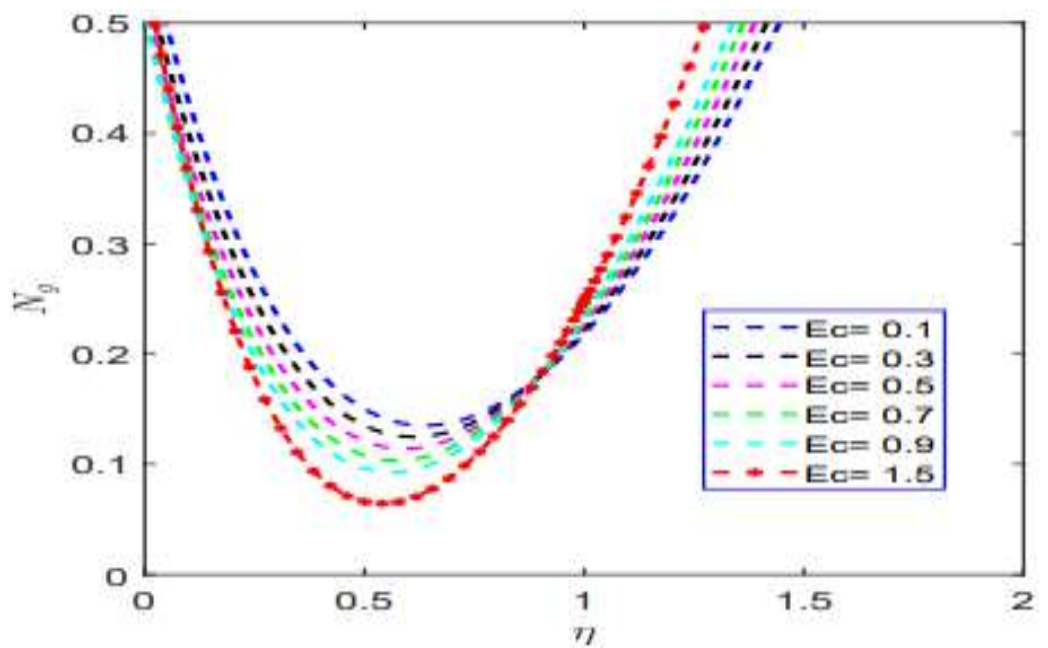

Figure 4. Influence of Eckert number on entropy generation

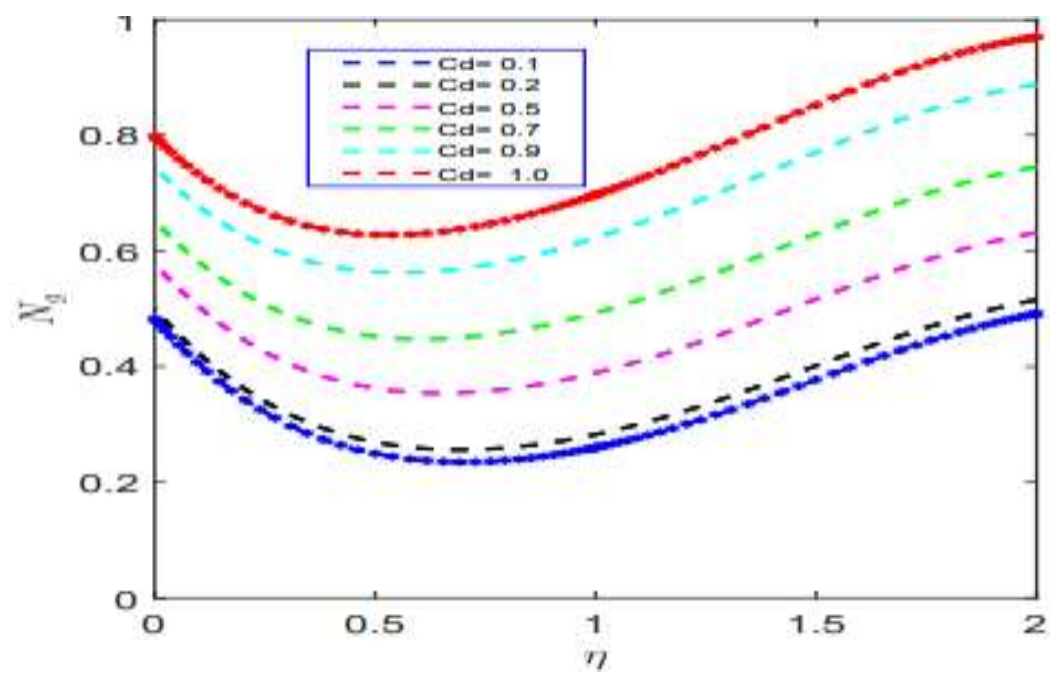

Figure 5. Influence of concentration difference parameter on entropy generation 
Figure 6 shows the influence of the diffusion coefficient on entropy generation. An increase in diffusion coefficient leads to an increase in entropy generation. Increased diffusion coefficient parameter causes an increase in both the velocity gradient and temperature gradients of the nanofluid, leading to increased entropy generation. Figure 7 shows the influence of the Prandtl number on entropy production. The Prandtl number increases the entropy generation near the plate due to increased friction irreversibility, while the opposite is observed at the center. Figure 8 shows the influence of the Hartmann number on entropy generation. Increased Hartmann number leads to an increase in the entropy generation. Near the Riga plate, the Hartmann number significantly influences entropy generation, while it has minor effects in the regions far away from the plate. The Hartmann number significantly increases the resistance to fluid motion; thus, the temperature rises, leading to an increase in the entropy production. Figure 9 displays the influence of the Brownian motion parameter on entropy generation. An increase in Brownian motion leads to an increase in entropy generation. The Brownian motion enhances micro-mixing that improves the nanofluid's thermal conductivity causing a temperature increase and an increased entropy generation rate.

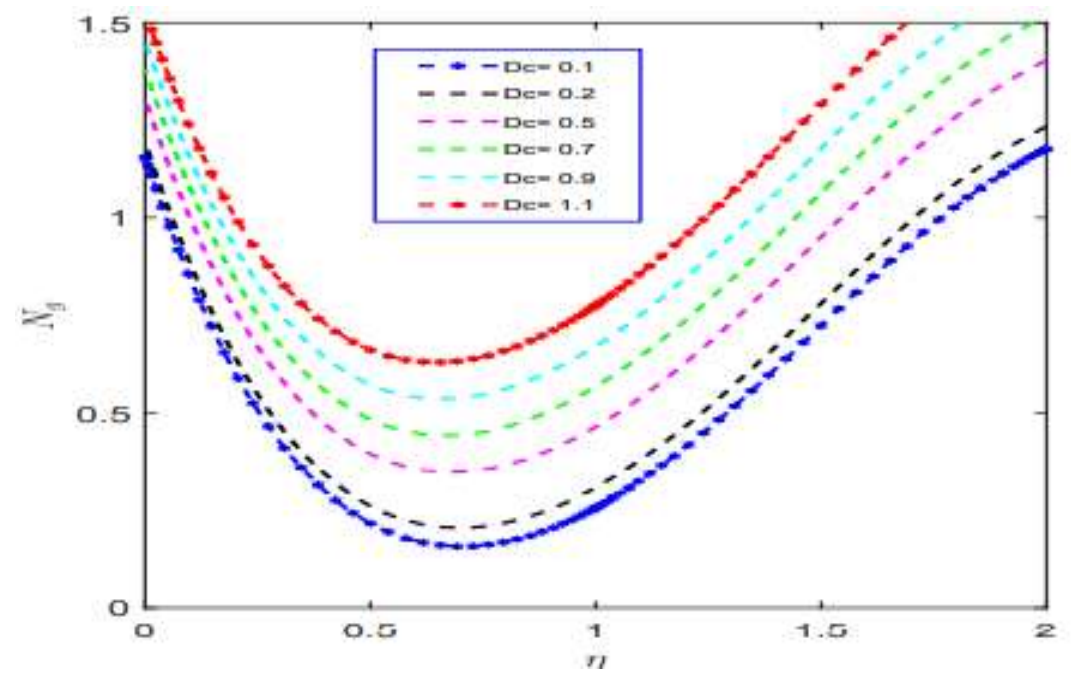

Figure 6. Influence of diffusion coefficient parameter on entropy generation

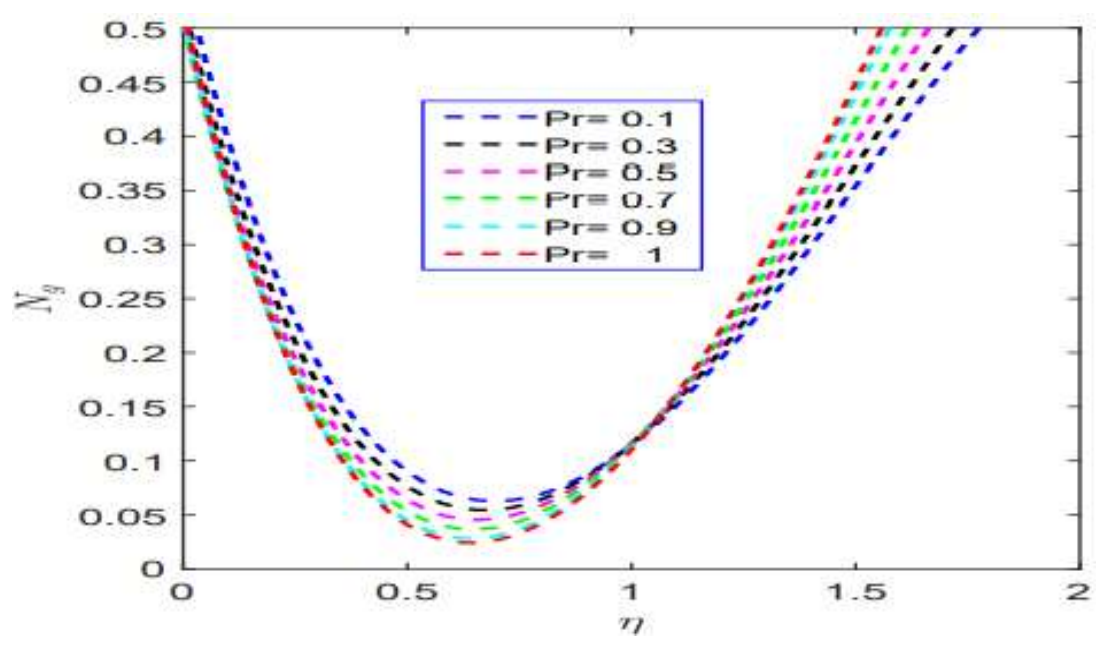

Figure 7. Influence of Prandtl number on entropy generation 


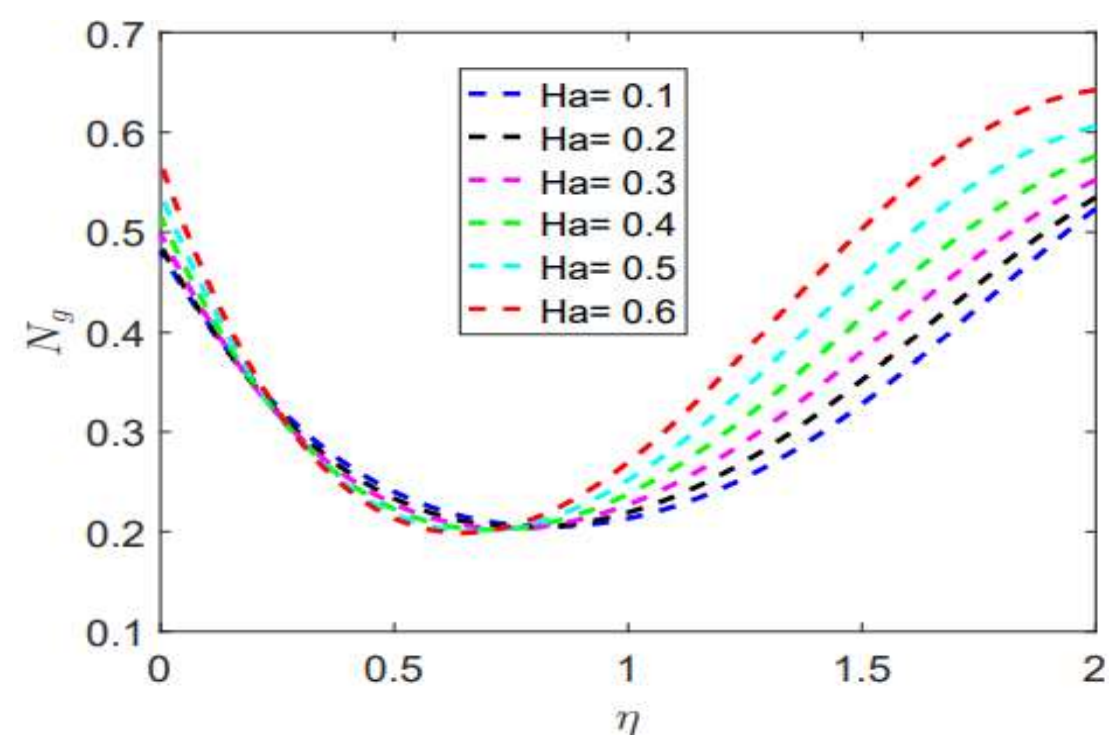

Figure 8. Influence of Hartmann number on entropy generation

Figure 11 shows the influence of the temperature difference parameter on entropy generation. A rise in temperature difference between the fluid particles leads to a fall in the entropy generation. This can be explained by the fact that as the temperature difference between the fluid particles increases, less heat is transferred within the channel leading to less entropy is generated. Figure 12 shows the effect of varying both the Brinkman number and the Reynolds number on entropy generation. A rise in both of the parameters results in a rise in entropy production. This is expected because both the inertia forces and temperature in the fluid increase with an increase in the two parameters resulting in high entropy generation. Figure 13 shows the effect of the Reynolds number and the temperature difference parameter simultaneously. An increase in both parameters leads to an increase in entropy generation. The inertia forces dominate the viscous forces when both the Reynolds number and the temperature difference parameter increases causing a rise in the fluid's temperature boosting entropy production.

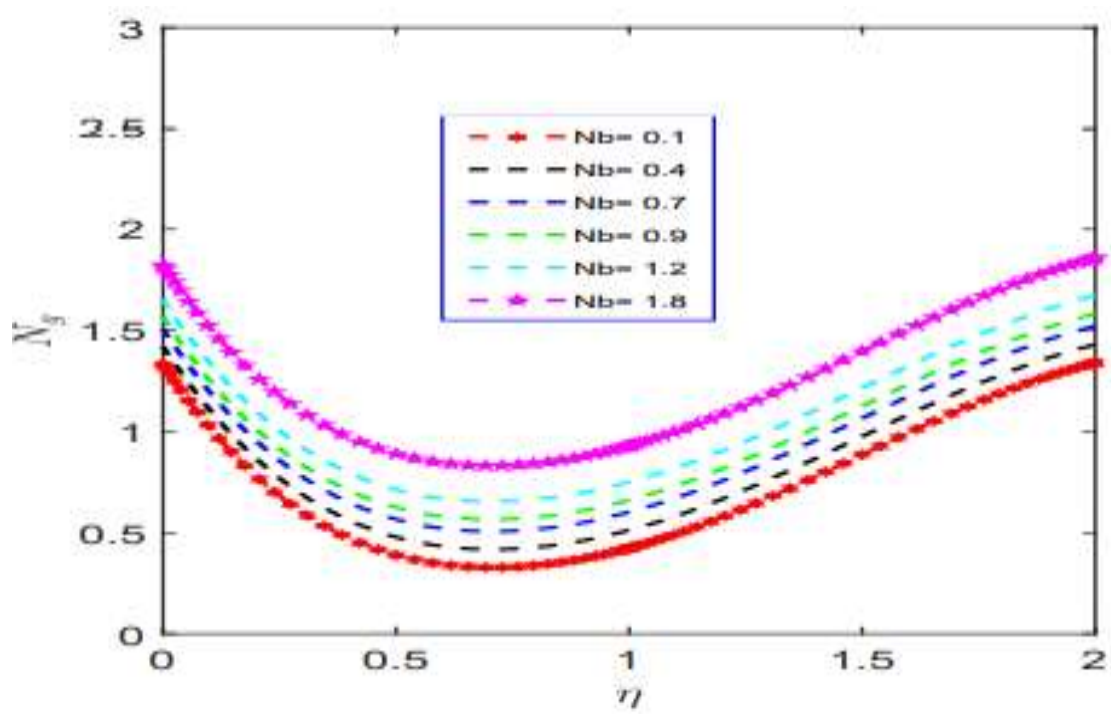

Figure 9. Influence of Brownian motion parameter on entropy generation 
Journal of Thermal Engineering, Research Article, Vol. 7, No. 4, pp. 845-866, May, 2021

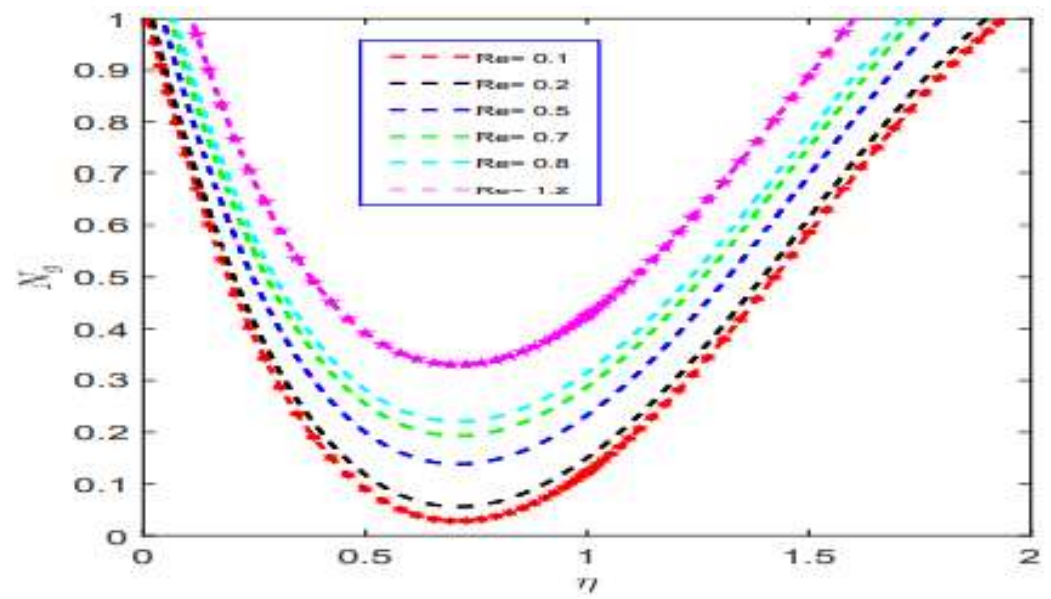

Figure 10. Influence of Reynolds number on entropy generation

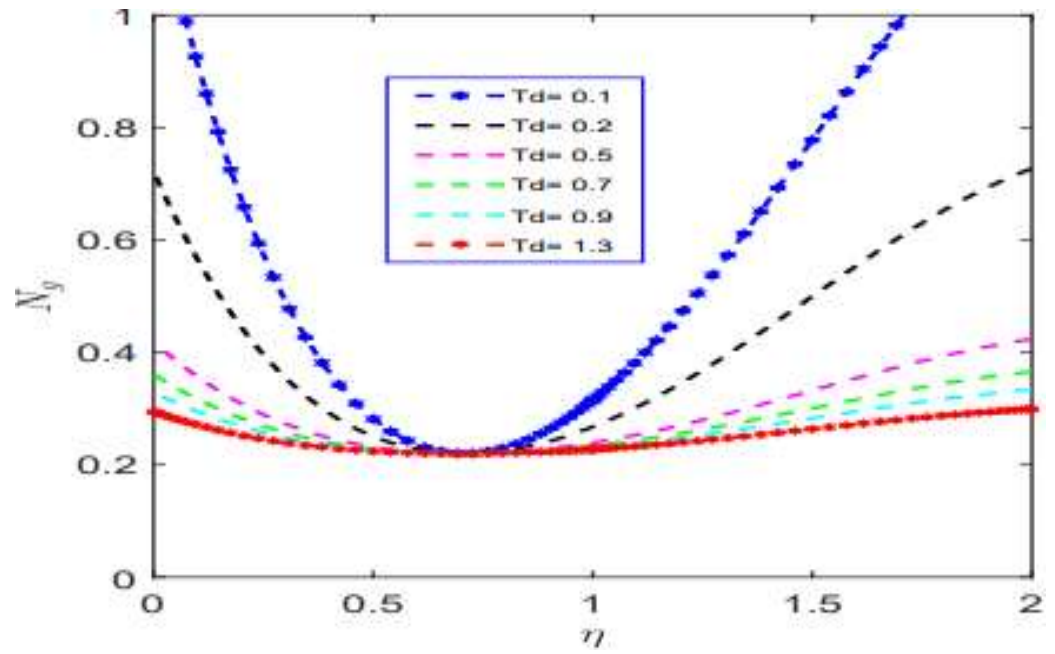

Figure 11. Influence of temperature difference parameter on entropy generation

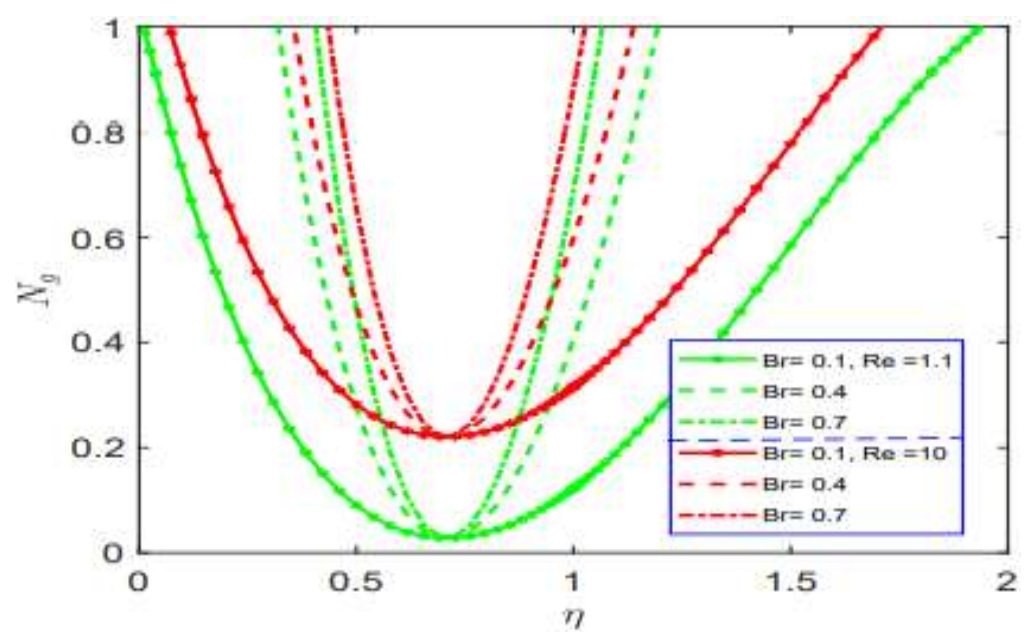

Figure 12. Influence of both Brinkmann number and Reynolds number on entropy generation

Figure 14 shows the effect of both the concentration difference parameter and the Reynolds number on 
entropy generation. An increase in both parameters leads to an increase in entropy generation. Figure 15 shows the effect of both the Brinkman number and the Hartmann number on entropy generation. An increase in both parameters translates to a rise in entropy production. An increase in both parameters means both viscous dissipation and electromagnetic force, causing an increase in entropy generation.

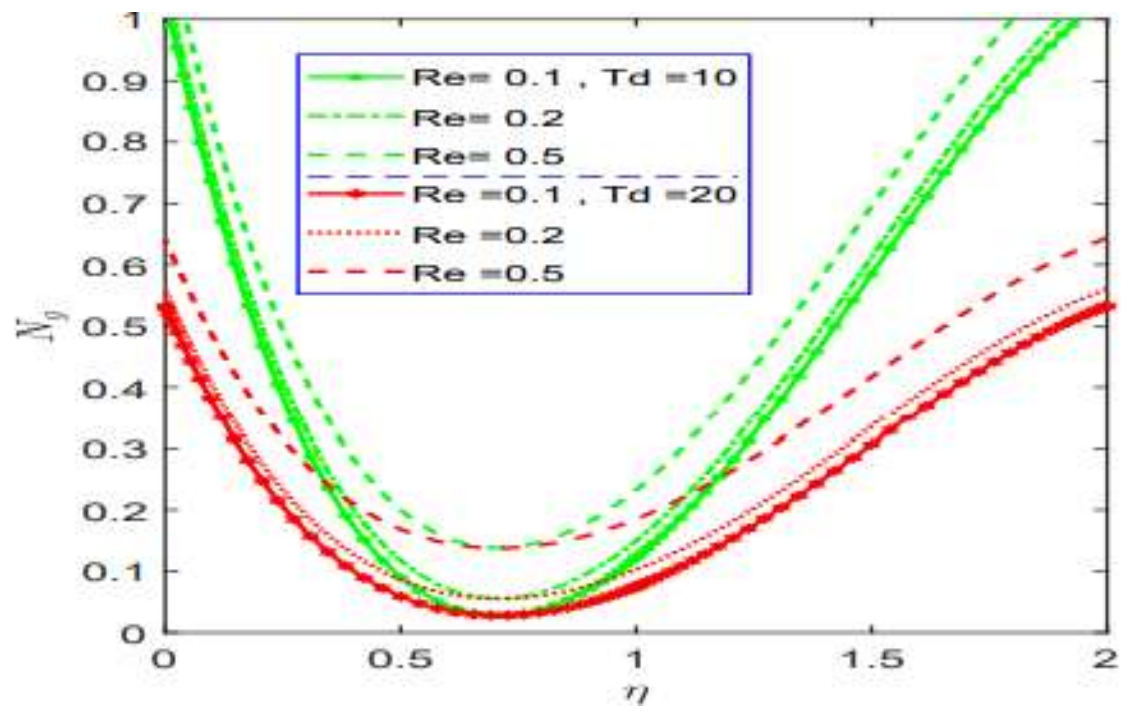

Figure 13. Influence of both temperature difference parameter and Reynolds number on entropy generation

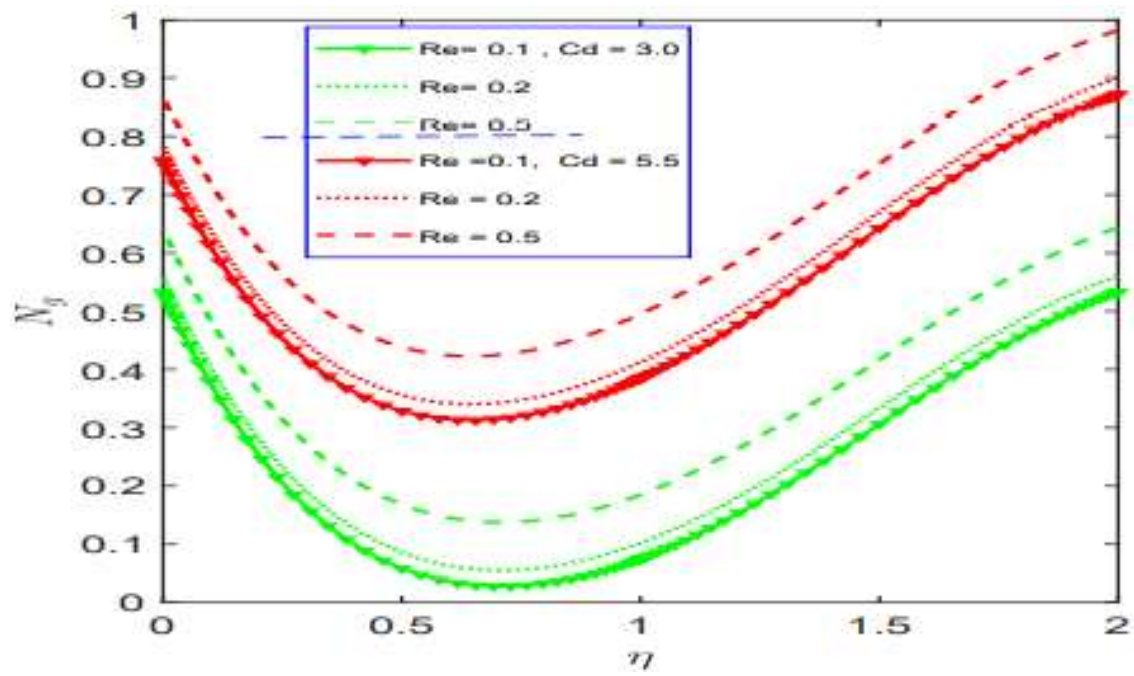

Figure 14. Influence of both concentration difference parameter and Reynolds number on entropy generation

Figure 16 demonstrates the effect of varying both the Reynolds number and the Brownian motion on entropy generation. An increase in both parameters leads to an increase in entropy generation. An increase in both the parameters translates to an increase in molecular collisions and inertial forces, leading to increased entropy generation. Figures 17 and 18 show the Deborah number's influence in both the relaxation time and retardation time, respectively, on the entropy generation rate. The Deborah number quantifies the observation that, with sufficient time, a solid-like material might flow or a fluid-like material may behave like a solid when deformed quickly. Increasing the Deborah's number in relaxation time significantly reduces the fluid motion causing a reduction in the thermal, thermal boundary layer and a decline in the entropy generation. In contrast, the opposite is observed when the Deborah number in retardation time is increased. Figure 19 demonstrates the effect of the Riga plate width parameter on entropy 
generation. An increase in the width parameter leads to an increase in entropy generation. Increased width parameter significantly increases the resistance to fluid motion, as a result of which the temperature rises, leading to an increase in the entropy production. Figure 20 shows the influence of the thermophoresis parameter on entropy production. A rise in the thermophoresis parameter leads to a rise in entropy generation. Close to the plate, the entropy generation decreases as the thermophoresis parameter increases. However, the thermophoresis parameter increases the amount of entropy generation away from the plate and within the boundary layer. The amount of entropy produced near the surface is higher, which means the surface is a significant irreversibility source.

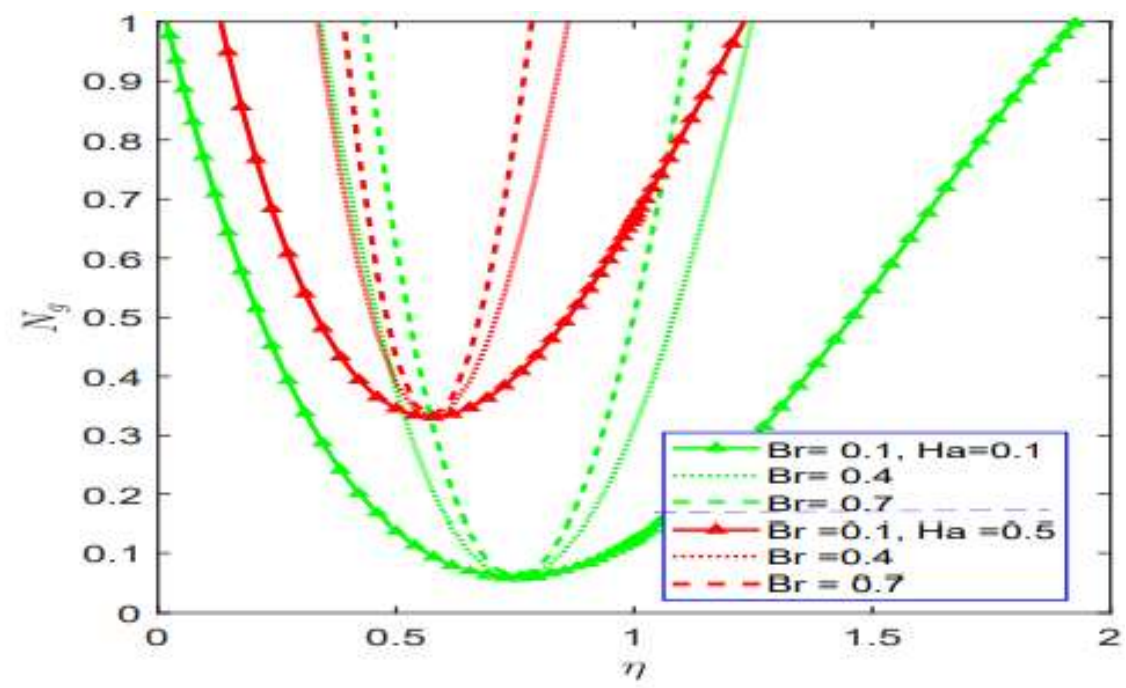

Figure 15. Influence of both Brinkmann number and Hartmann number on entropy generation

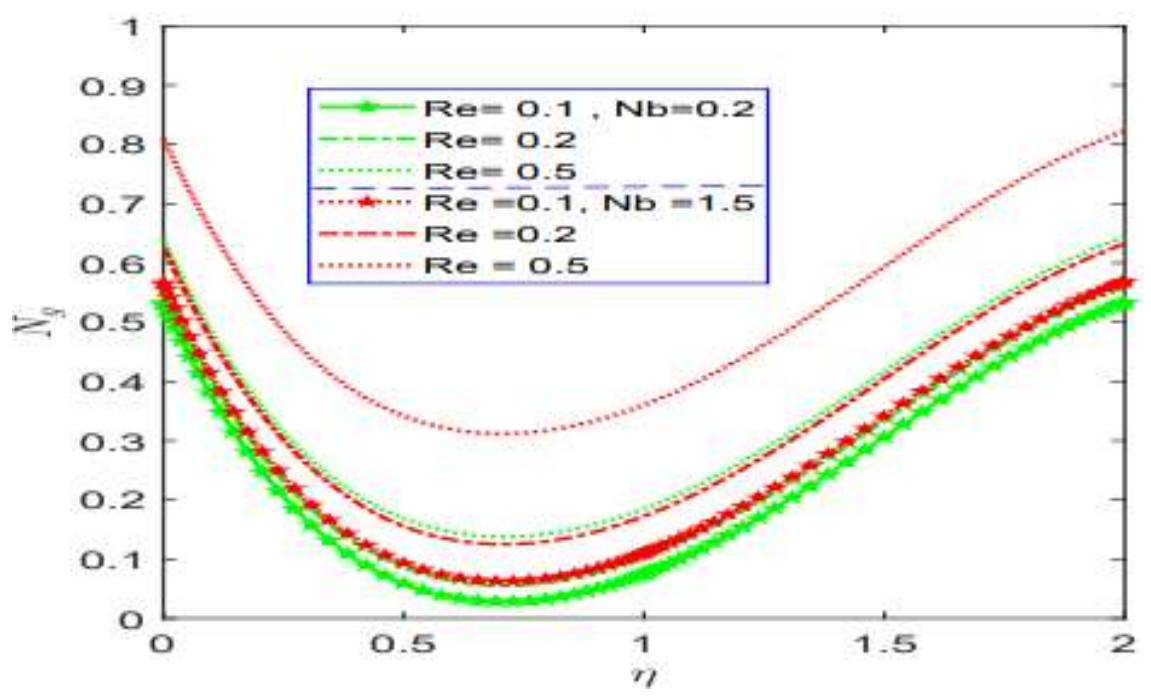

Figure 16. Influence of both Reynolds number and Brownian motion parameter on entropy generation 
Journal of Thermal Engineering, Research Article, Vol. 7, No. 4, pp. 845-866, May, 2021

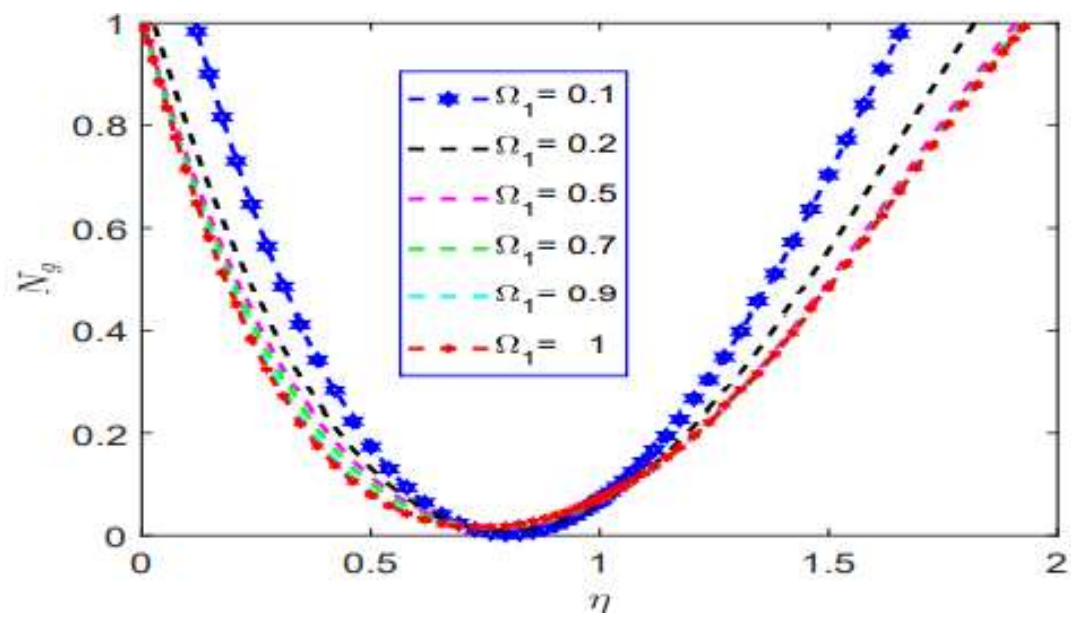

Figure 17. Influence of Deborah number in relaxation time on entropy generation

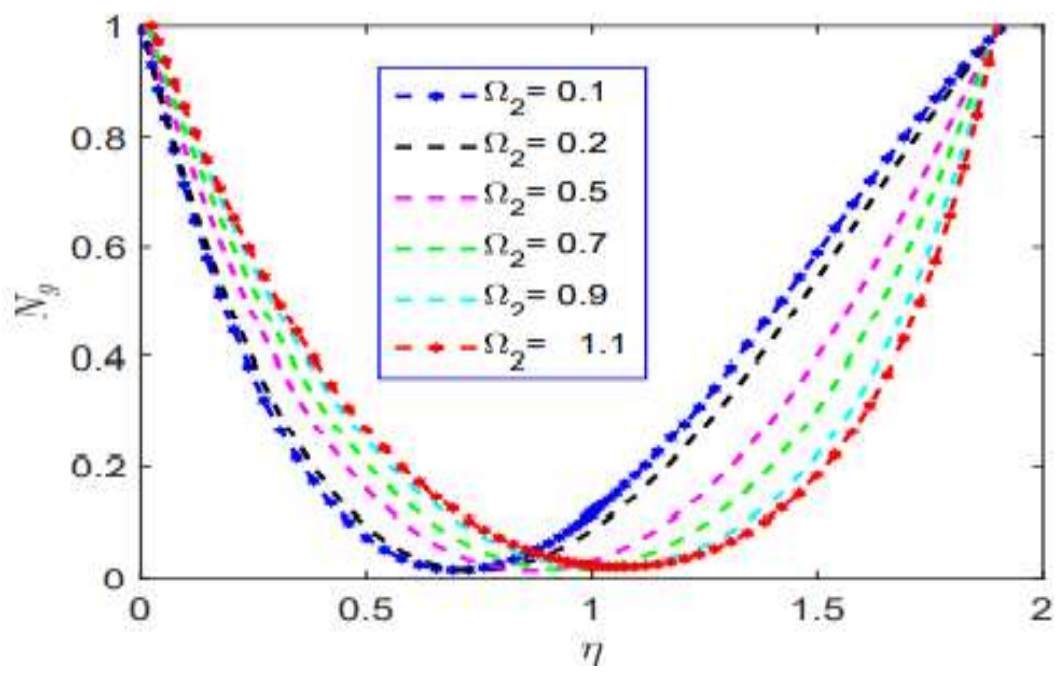

Figure 18. Influence of Deborah number in retardation time on entropy generation

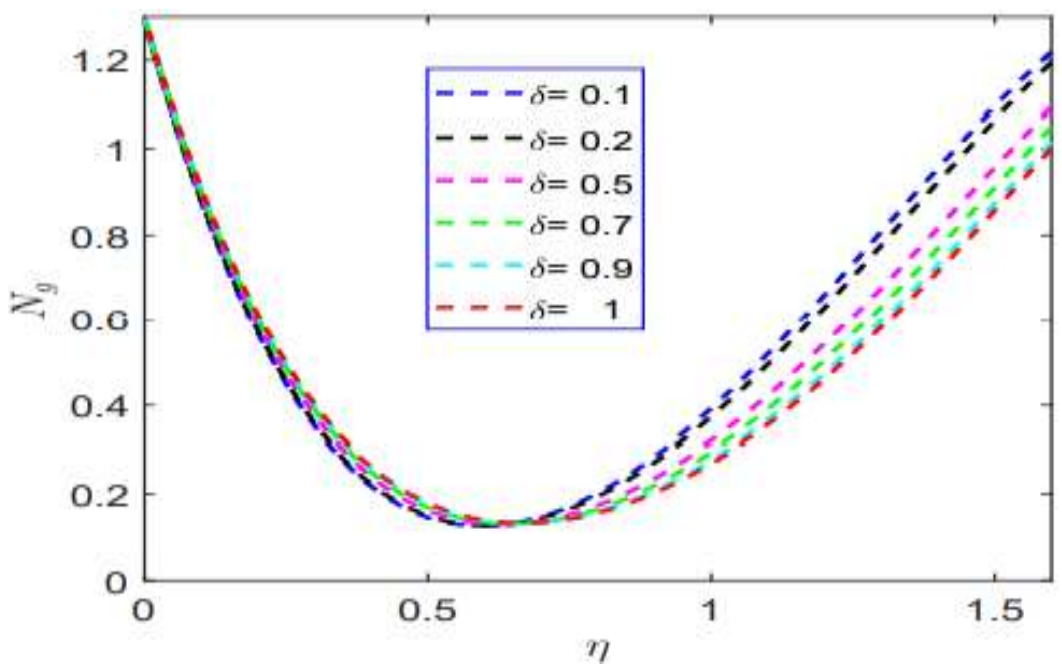

Figure 19. Influence of width parameter on entropy generation 


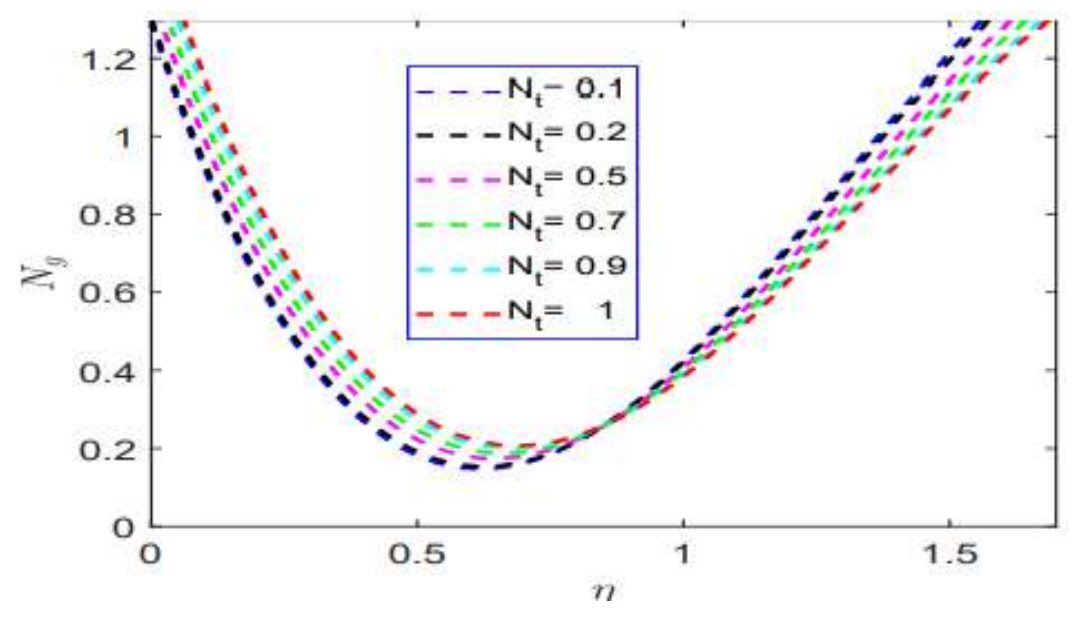

Figure 20. Influence of thermophoresis parameter on entropy generation

\section{CONCLUSION}

The study presented a numerical investigation of entropy generation in an Oldroyd-B nanofluid flow past a Riga plate. The highly nonlinear differential equations system was linearized using the QLM scheme and solved numerically using a new spectral collocation method with overlapping grids. Sensitivity and convergence analysis for the method was presented, and the method was confirmed to be stable and convergent for a system of ODEs. The impact of several parameters on entropy generation was determined. The following are the main conclusions drawn from this study:

- An increase in the Hartman number lead to an increase in entropy generation.

- An increase in the width of the Riga plate lead to an increase in entropy generation.

- An increase in Brinkman number leads to an increase in entropy generation.

- Increasing the thermophoresis parameter leads to an increase in entropy generation.

- Increasing the Eckert number leads to a decrease in entropy generation.

- Increasing the Brownian motion parameter leads to an increase in entropy generation.

- The overlapping grid spectral collocation method is accurate and converges fast.

\section{NOMENCLATURE}

$u \quad$ Velocity component in the $x$ direction

$v \quad$ Velocity component in the $y$ direction

$M_{h} \quad$ Electromagnetic field of the Riga-plate

$u_{w}(x, t) \quad$ Plate velocity

$u_{e}(x, t) \quad$ Free stream velocity

$T \quad$ Fluid temperature

$T_{\infty} \quad$ Temperature of the ambient fluid

$T_{w} \quad$ Constant temperature on the surface of the plate

C Fluid concentration

$C_{\infty} \quad$ Concentration of the ambient fluid

$C_{w} \quad$ Constant concentration on the surface of the plate

$F(\eta) \quad$ Dimensionless stream function with respect to $\eta$ 


$\begin{array}{ll}q^{r} & \text { Rosseland approximation } \\ H_{a} & \text { Modified Hartman number } \\ P r & \text { Prandtl number } \\ E c & \text { Eckert number } \\ N_{b} & \text { Brownian motion parameter } \\ N_{t} & \text { Thermophoresis parameter } \\ S c & \text { Schmidt number } \\ R d & \text { Conduction-radiation parameter } \\ R e & \text { Reynolds number } \\ B r & \text { Brinkmann number } \\ N_{G} & \text { Entropy generation }\end{array}$

Greek symbols

$\begin{array}{ll}\eta & \text { Non-dimensional vertical distance } \\ \sigma_{1} & \text { Stefan-Boltzmann constant } \\ \chi & \text { Mean absorption coefficient } \\ \Omega_{1} & \text { Deborah numbers in terms of relaxation time } \\ \Omega_{2} & \text { Deborah numbers in terms of retardation time } \\ \varepsilon & \text { Variable viscosity parameter } \\ \delta & \text { Width parameter } \\ \gamma & \text { Chemical reaction parameter } \\ \beta & \text { Velocity ratio parameter } \\ \Psi & \text { Dimensionless temperature difference } \\ \varrho & \text { Dimensionless concentration difference } \\ \Lambda & \text { Diffusion coefficient }\end{array}$

Subscripts

$f \quad$ Refers to fluid

\section{REFERANCES}

[1] Gailitis AK, Lielausis OA. On the possibility of drag reduction of a flat plate in an electrolyte. Appl. Magnetohydrodyn. Trudy Inst. Fisiky AN Latvia SSR. 1961;12:143.

[2] Avilov VV. Electric and magnetic fields for the Riga plate. FZR Interner Bericht. 1998.

[3] Hayat T, Ullah I, Alsaedi A, Ahamad B. Simultaneous effects of nonlinear mixed convection and radiative flow due to Riga-plate with double stratification. Journal of Heat Transfer. 2018; 140 (10):102008. https://doi.org/10.1115/1.4039994.

[4] Rana P, Shukla N. Entropy generation analysis for the non-similar analytical study of nanofluid flow and heat transfer under the influence of the aligned magnetic field. Alexandria engineering journal. 2018; 57(4),3299-3310. https://doi.org/10.1016/j.aej.2017.12.007.

[5] Nayak MK, Shaw S, Makinde OD, Chamkha AJ. Investigation of partial slip and viscous dissipation effects on the radiative tangent hyperbolic nanofluid flow past a vertical permeable Riga plate with internal heating: Buongiorno model. Journal of Nanofluids. 2019; 8(1):51-62.

[6] Shaw S, Sen SS, Nayak MK, Makinde OD. Boundary layer nonlinear convection flow of Sisko 
nanofluid with melting heat transfer over an inclined permeable electromagnetic sheet. Journal of Nanofluids. 2019; 8(5):917-928. https://doi.org/10.1166/jon.2019.1649.

[7] Das M, Mahanta G, Shaw S, Parida SB. Unsteady MHD chemically reactive double-diffusive Casson fluid past a flat plate in a porous medium with heat and mass transfer. Heat Transfer-Asian Research. 2019; 48(5):1761-1777. https://doi.org/10.1002/htj.21456.

[8] Nayak MK, Shaw S, Chamkha AJ. 3D MHD free convective stretched flow of a radiative nanofluid inspired by a variable magnetic field. Arabian Journal for Science and Engineering. 2019; 44(2): 12691282. https://doi.org/10.1007/s13369-018-3473-y.

[9] Kundu B. Semi-analytical methods for heat and fluid flow between two parallel plates. Journal of Thermal Engineering. 2015; 1(3):175-181. https://doi.org/10.18186/jte.12495.

[10] Hussein AK, Mustafa AW. Natural convection in a parabolic enclosure with an internal vertical heat source filled with $\mathrm{Cu}-$ water nanofluid. Heat Transfer-Asian Research. 2018; 47(2):320-336. https://doi.org/10.1002/htj.21305.

[11] Kerme E, Orfi J. Exergy-based thermodynamic analysis of solar-driven organic Rankine cycle. Journal of Thermal Engineering. 2015; 1(5):192-202. https://doi.org/10.18186/jte.25809.

[12] Gaikwad VP, Mohite SS, Shinde SS, Dherange ML. Enhancement in thermo-hydraulic performance of microchannel heat sink with secondary flows of leaf venation pattern. Journal of Thermal Engineering. 2020; 6(5):677-696.

[13] Nashine P, Singh TS. Effect of dean number on the heat transfer characteristics of a helical coil tube with variable velocity and pressure inlet. Journal of Thermal Engineering. 2020;6(2):128-139. https://doi.org/10.18186/thermal.729149.

[14] Rudolf E, Eckert G, Drake RM. Analysis of heat and mass transfer. 1987.

[15] Gunn DJ. Transfer of heat or mass to particles in fixed and fluidized beds. International Journal of Heat and Mass Transfer. 1978; 21(4):467-476. https://doi.org/10.1016/0017-9310(78)90080-7.

[16] Singh PK, Anoop KB, Sundararajan T, Das SK. Entropy generation due to flow and heat transfer in nanofluids. International Journal of Heat and Mass Transfer. 2010; 53(21-22):4757-4767. https://doi.org/10.1016/j.ijheatmasstransfer.2010.06.016.

[17] Chen S, Tian Z. Entropy generation analysis of thermal micro-Couette flows in slip regime. International Journal of Thermal Sciences. 2010; 49(11):2211-2221.

[18] Lucia U. Molecular machine as chemical-thermodynamic devices. Chemical Physics Letters. 2013; 556:242-244. https://doi.org/10.1016/j.cplett.2012.11.064.

[19] Rehman AU, Mehmood R, Nadeem S. Entropy analysis of radioactive rotating nanofluid with thermal slip. Applied Thermal Engineering. 2017; 112:832-840.

[20] Rashed AA, Kalidasan K, Kolsi L, Velkennedy R, Aydi A, Hussein AK, Malekshah EH. Mixed convection and entropy generation in a nanofluid filled cubical open cavity with a central isothermal block. International Journal of Mechanical Sciences. 2018; 135:362-375. https://doi.org/10.1016/j.ijmecsci.2017.11.033.

[21] Ahmed SE, Hussein AK, Mansour MA, Raizah ZA, Zhang X. MHD mixed convection in trapezoidal enclosures filled with micropolar nanofluids. Nanoscience and Technology: An International Journal. 2018; 9(4).

[22] Chand R, Rana GC, Hussein AK. Effect of suspended particles on the onset of thermal convection in a nanofluid layer for more realistic boundary conditions. International Journal of Fluid Mechanics Research. 2015; 42(5). 10.1615/InterJFluidMechRes.v42.i5.10.

[23] Hussein AK, Hussain SH. Heat line visualization of natural convection heat transfer in an inclined wavy cavity filled with nanofluids and subjected to a discrete isoflux heating from its left sidewall. Alexandria Engineering Journal. 2016; 55(1):169-186.

[24] Hussein AK, Bakier M, Hamida MB, Sivasankaran S. Magneto-hydrodynamic natural convection in an inclined t-shaped enclosure for different nanofluids and subjected to a uniform heat source. Alexandria Engineering Journal. 2016; 55(3):2157-2169.

[25] Shaw S, Nayak MK, Makinde OD. The transient rotational flow of radiative nanofluids over an impermeable Riga plate with variable properties. In Defect and Diffusion Forum. 2018; volume 387, pages 640-652. https://doi.org/10.4028/www.scientific.net/DDF.387.640.

[26] Esfahani JA, Akbarzadeh M, Rashidi S, Rosen MA, Ellahi R. Influences of wavy wall and nanoparticles on entropy generation overheat exchanger plat. International Journal of Heat and 
Mass Transfer. 2017; 109:1162-1171.

[27] Bhatti MM, Rashidi MM, Pop I. Entropy generation with nonlinear heat and mass transfer on MHD boundary layer over a moving surface using SLM. Nonlinear Engineering. 2017; 6(1):43-52. https://doi.org/10.1515/nleng-2016-0021.

[28] Shashikumar NS, Gireesha BJ, Mahanthesh B, Prasannakumara BC, Chamkha AJ. Entropy generation analysis of magneto-nanoliquids embedded with aluminum and titanium alloy nanoparticles in a microchannel with partial slips and convective conditions. International Journal of Numerical Methods for Heat \& Fluid Flow. 2018.

[29] Walvekar R, Singh A, Khalid M, Gupta TCSM, Yin W. Thermophysical properties of deep eutectic solvent-carbon nanotubes (descent) based nano lubricant. Journal of Thermal Engineering. 2018; 6(2):53-64. https://doi.org/10.18186/thermal.726059.

[30] Almakki M, Mondal H, Sibanda P. Entropy generation in MHD flow of viscoelastic nanofluids with homogeneous-heterogeneous reaction, partial slip and nonlinear thermal radiation. Journal of Thermal Engineering. 2020;6(3):327-345. https://doi.org/10.18186/thermal.712452

[31] Selimefendigil F. Experimental investigation of nano compressor oil effect on the cooling performance of a vapor-compression refrigeration system. Journal of Thermal Engineering. 2019; 5(1):100-104. https://doi.org/10.18186/thermal.513023.

[32] Akinshilo A. Analytical decomposition solutions for heat transfer on straight fins with temperaturedependent thermal conductivity and internal heat generation. Journal of Thermal Engineering. 2019; 5(1):76-92. https://doi.org/10.18186/thermal.505489.

[33] Ekiciler R, Aydeniz E, Arslan K. A CFD investigation of $\mathrm{Al}_{2} \mathrm{O}_{3}$ /water flow in a duct having a backwardfacing step. Journal of Thermal Engineering. 2019; 5(1):31-41.

[34] Shaw S, Dogonchi AS, Nayak MK, Makinde OD. Impact of entropy generation and nonlinear thermal radiation on Darcy-Forchheimer flow of $\mathrm{MnFe}_{2} \mathrm{O}_{4}$-Casson/water nanofluid due to a rotating disk: Application to brain dynamics. Arabian Journal for Science and Engineering. 2020; pages 1-20.

[35] Farooq U, Afridi M, Qasim M, Lu D. Transpiration and viscous dissipation effects on entropy generation in hybrid nanofluid flow over a nonlinear radially stretching disk. Entropy. 2018; 20 (9):668. https://doi.org/10.3390/e20090668.

[36] Gupta S, Sandeep G. MHD three-dimensional flow of Oldroyd-B nanofluid over a bidirectional stretching sheet: DTM-Padé solution. Nonlinear Engineering. 2019;8(1):744-754. https://doi.org/10.1515/nleng-2018-0047.

[37] Alshomrani AS, Irfan M, Salem A, Khan M. Chemically reactive flow and heat transfer of magnetite Oldroyd-B nanofluid subject to stratifications. Applied Nanoscience. 2018; 8(7):1743- 1754.

[38] Gireesha BJ, Kumar KG, Prasannakumar BC. Scrutinization of chemical reaction effect on flow and mass transfer of Prandtl liquid over a Riga plate in the presence of solutal slip effect. International Journal of Chemical Reactor Engineering. 2018;16(8). https://doi.org/10.1515/ijcre2018-0009.

[39] Nayak MK, Shaw S, Makinde OD, Chamkha AJ. Effects of homogenous-heterogeneous reactions on radiative $\mathrm{NaCl}-\mathrm{CNP}$ nanofluid flow past a convectively heated vertical Riga plate. Journal of Nanofluids. 2018; 7(4):657-667. https://doi.org/10.1166/jon.2018.1501.

[40] Kasmani RM, Sivasankaran S, Bhuvaneswari M, Hussein AK. Analytical and numerical study on convection of nanofluid past a moving wedge with Soret and Dufour effects. International Journal of Numerical Methods for Heat \& Fluid Flow. 2017.

[41] Karakurt S, Gunes U. A new approach for evaluating the Rankine cycle through entropy generation. Journal of Thermal Engineering. 5(6):141-148.

[42] Bayareh M. Numerical simulation and analysis of heat transfer for different geometries of corrugated tubes in a double pipe heat exchanger. Journal of Thermal Engineering. 2019; 5(4):293-301. https://doi.org/10.18186/thermal.581775.

[43] Afridi M, Qasim M, Hussanan A. Second law analysis of dissipative flow over a Riga plate with nonlinear Rosseland thermal radiation and variable transport properties. Entropy. 2018; 20(8): 615. https://doi.org/10.3390/e20080615.

[44] Seini IY, Makinde OD. Boundary layer flow near stagnation-points on a vertical surface with slip in the presence of a transverse magnetic field. International Journal of Numerical Methods for Heat \& Fluid Flow. 2014; 24(3):643-653. 
Journal of Thermal Engineering, Research Article, Vol. 7, No. 4, pp. 845-866, May, 2021

[45] Bejan A. The thermodynamic design of heat and mass transfer processes and devices. International Journal of Heat and Fluid Flow. 1987;8(4):258-276. https://doi.org/10.1016/0142-727X(87)90062-2.

[46] Hayat T, Khan M, Imtiaz M, Alsaedi A. Squeezing flow past a Riga plate with chemical reaction and convective conditions. Journal of Molecular Liquids. 2017;225:569-576. https://doi.org/10.1016/j.molliq.2016.11.089.

[47] Raptis A. Radiation and free convection flow through a porous medium. International Communications in Heat and Mass Transfer. 1998; 25(2):289-295.

[48] Waqas M, Ijaz M, Khan, Hayat T, Alsaedi A. Stratified flow of an Oldroyd-B nanoliquid with heat generation. Results in Physics. 2017; 7:2489-2496.

[49] Bellman RE, Kalaba. Quasilinearization and nonlinear boundary value problems. 1965.

[50] Trefethen LN. Spectral methods in MATLAB. 2000; volume 10. Siam. 